\title{
Study on Passive and Semiactive Control Systems in Structures under Near- and Far-Field Earthquakes
}

\author{
Mohammadreza Zamanian, ${ }^{1}$ Ali Kheyroddin $\mathbb{D}^{2},{ }^{2}$ and Alireza Mortezaei ${ }^{1}{ }^{1}$ \\ ${ }^{1}$ Department of Civil Engineering, Semnan Branch, Islamic Azad University, Semnan, Iran \\ ${ }^{2}$ School of Civil Engineering, College of Engineering, University of Semnan, Semnan, Iran \\ Correspondence should be addressed to Ali Kheyroddin; kheyroddin@semnan.ac.ir
}

Received 20 June 2021; Accepted 6 January 2022; Published 11 February 2022

Academic Editor: Shuang Li

Copyright (C) 2022 Mohammadreza Zamanian et al. This is an open access article distributed under the Creative Commons Attribution License, which permits unrestricted use, distribution, and reproduction in any medium, provided the original work is properly cited.

\begin{abstract}
The construction demand for irregular structures is increasing due to the population growth of cities, limited construction areas, and the aesthetics of structures. Lack of proper understanding on the dynamic behavior of these structures during seismic events can lead to local and global failures on them. In order to investigate this issue, we used a regular 10-story structure with three different stiffness irregularity cases along the elevation. Irregularities are considered in three positions: the lower half of the structure height, the lowest story, and the middle story. In this study, to reduce the damage and mitigate the seismic response of the structure, three control systems are proposed including a magnetorheological (MR) damper with semiactive fuzzy controller as the semiactive control system, a Tuned Mass Damper (TMD) as the passive control system, and the simultaneous use of them. Based on the numerical analyses under near- and far-field ground motions, the residual plastic deformations are significantly reduced by the simultaneous use of MR damper and TMD, while each of these dampers alone performs poorly in some cases. The results show that if these two dampers are used together, a more promising control system with robust performance against changes in system parameters can be achieved.
\end{abstract}

\section{Introduction}

The growth of technology in the field of modern structures has been able to facilitate the construction of structures, which were previously restricted in the codes due to their unknown behaviors. Today, the human need to make the best use of available space can cause various irregularities in the structure. For instance, through the process of analysis and design of a structure against the applied loads, making decisions about configuration, geometric characteristics of the structure such as dimensions in plan and elevation, and the role of structural and nonstructural components can create irregularities in the structure. In regular structures, the seismic force is uniformly transmitted upward from the ground level, while, in irregular structures, this force is unevenly distributed throughout the structure. For this reason, it is necessary to investigate the dynamic performance of this kind of structures and propose strategies to provide a solution to reduce unexpected responses.
Observing the behavior of irregular structures during the earthquake, this issue has been investigated by many researchers since 1970. Extensive studies on plan irregularity [1] and limited studies on vertical irregularity in structures have been conducted. However, in the recent few years, research in this area has also grown significantly. Investigation of structural damage related to recent earthquakes such as the Aegean Sea earthquake shows major failures due to vertical stiffness irregularities in multi-story structures [2]. Michalis et al. [3] evaluated the behavior of vertically irregular structures using the Incremental Dynamic Analysis (IDA) method. The authors studied a 9-story steel frame known as LA9 by examining all four types of vertical irregularities: stiffness, strength, combined stiffness-strength, and mass irregularity. The results showed that the effects of vertical irregularity on the structural performance level depend on the type of irregularity, the story in which the irregularity occurs, and most importantly the severity of the 
seismic excitation. Le-Trung et al. [4] investigated the seismic behavior of vertically irregular building structures with moment resisting steel frames. They examined three types of vertical irregularities including mass, stiffness, and strength irregularity and performed nonlinear static and dynamic analyses. Oyguc et al. [5] investigated the degradation behavior of three irregular reinforced concrete structures under the Tohoku earthquake using three-dimensional models. These models included a proper form of damage to study the effect of irregularity and degradation of the materials. Naveen et al. [6] investigated a 9-story concrete structure with different irregularity cases. The numerical simulations showed that the structural response is significantly affected by the irregularity [7]. They also concluded that the stiffness irregularity has the greatest effect on the structural responses. One of the challenges for researchers and engineers is to provide a suitable solution to reduce the structural vibrations. With the recent losses of life, property, and remarkable damage to structures due to the earthquakes, structural vibration control techniques are becoming more critical for public safety. Many studies have used passive control devices such as isolation bearings [8], viscous and viscoelastic damping devices $[9,10]$, friction dampers [11], and other types of innovative damping devices $[12,13]$ to reduce the response of irregular structures. The seismic performance evaluation of structures in the past earthquakes shows that asymmetry and improper distribution of mass, stiffness, and strength are among the main sources of damage due to the torsion in the floors. Many studies have been conducted on the seismic response of asymmetric structures and the enhancement of their torsional behavior. Nigdeli and Boduroglu [14] employed active tendons to control the torsional vibrations of irregular single- and multistory structures subjected to near-field earthquakes. In their research, the control signals were determined by a Proportional-Integral-Derivative (PID) controller. The results showed that the controller can reduce the maximum translational and rotational response by considering the time delay. Mazza [15] investigated the reliability of irregular structures isolated at foundation level. Sonawane and Walzade [8] used an isolation system to reduce the response of regular and irregular structures. A Tuned Mass Damper (TMD) instead is comprised of a lumped mass together with spring and damper elements [16]. This device works based on the inertial force created in the lumped mass. If the mechanical properties of the device do not change during an earthquake, it will act as a passive damper. Soto and Adeli [17] investigated the optimal tuning of TMDs for high-rise structures with plan irregularity using conventional relationships. Babaei and Moniri [18] employed a TMD to reduce the vibrations of a 10-story structure with mass irregularity. The mass ratio of the TMD in their study was assumed to be $2 \%$. The results showed that the TMD improves the performance of irregular structures. But the performance is not significant in near-field earthquakes with strong pulses. In order to compensate for the downsides of passive dampers, semiactive and active systems were proposed. Among them, magnetorheological (MR) dampers with intrinsic properties such as very fast response time, reversible phase, robustness against surrounding environment, and effective controllability have been studied by numerous researchers. Bathaei et al. [19] employed a combination of TMD and MR dampers to control the vibrations of an 11-degree-of-freedom system. By adding the MR damper to the TMD system, the authors increased the adaptability during the vibrations. Javadinasab Hormozabad and Ghorbani-Tanha [20] investigated the seismic control of cable-stayed bridges using MR dampers and semiactive fuzzy controllers. The authors created a comprehensive $3 \mathrm{D}$ nonlinear model of the Lali Cable-Stayed Bridge considering material and geometrical nonlinearities as well as prestress forces in stay cables and evaluated the performance of several fuzzy controllers on the bridge. MR dampers together with fuzzy controllers were also employed to propose a mobile TMD device for vibration control of sagged stay cables [21]. The proposed system incorporated fuzzy algorithms to control the performance of MR dampers and a locating algorithm to find the optimal location of the semiactive device along the cable. The numerical evaluations using different load patterns showed remarkable improvement compared with passive and nonmoving devices. In control systems, accurate computing with the lowest computational cost is an important advantage [22].

In the present study, a semiactive control system with MR dampers, a passive control system with TMD, and a combined control system with simultaneous use of these two devices are investigated to reduce the vibrations of structures with stiffness irregularity. One of the gaps of previous studies is the lack of attention to the characteristics of the structures in vibration control. Because there is an irregularity in the controlled structure at a certain level, it can cause local stresses in other parts of the structure. It can also behave differently in near- and far-field earthquakes because these loads are fundamentally different. Furthermore, fuzzy controllers, designed by experts in the field to make the necessary decisions in real-time, can be challenging for structures with more complexity compared to regular structures. In terms of the type of damper, each damper alone has its advantages and disadvantages. In the present study, the two dampers are employed simultaneously to compensate for the disadvantages. Therefore, in order to bridge the gap in the studies conducted in this field, various variables such as the type of earthquake, stiffness irregularity in different stories, the performance of controllers, and the simultaneous use of the two dampers are examined.

\section{Case Study}

In the present study, a 10-storey structure with a story height of $3 \mathrm{~m}$ and a bay width of $5 \mathrm{~m}$ in each direction in plan is used as a regular structure (Figure 1(a)). The lateral load resisting system of the structure is a special moment resisting steel frame in both directions. The floors are defined using two-way concrete slabs with a rigid diaphragm. The structure is designed for the zone with a high relative seismic risk and a site with type 2 soil. The distributed dead and live loads acting on the floor are $700 \mathrm{~kg} / \mathrm{m}^{2}$ and $200 \mathrm{~kg} / \mathrm{m}^{2}$, respectively. 

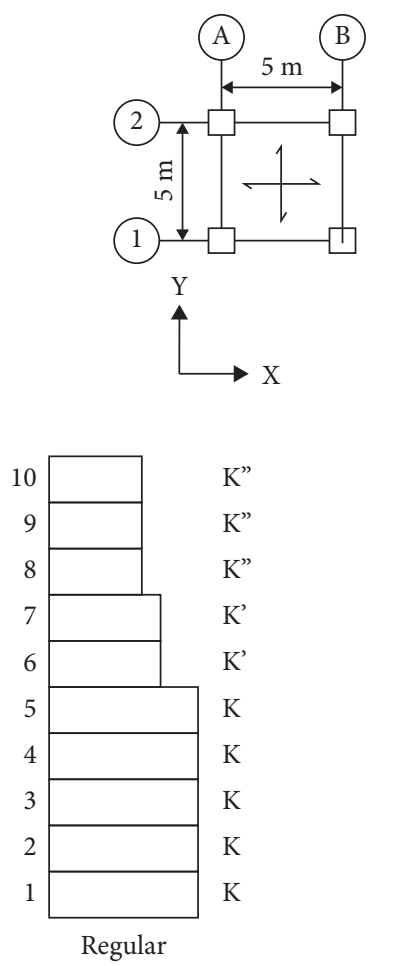

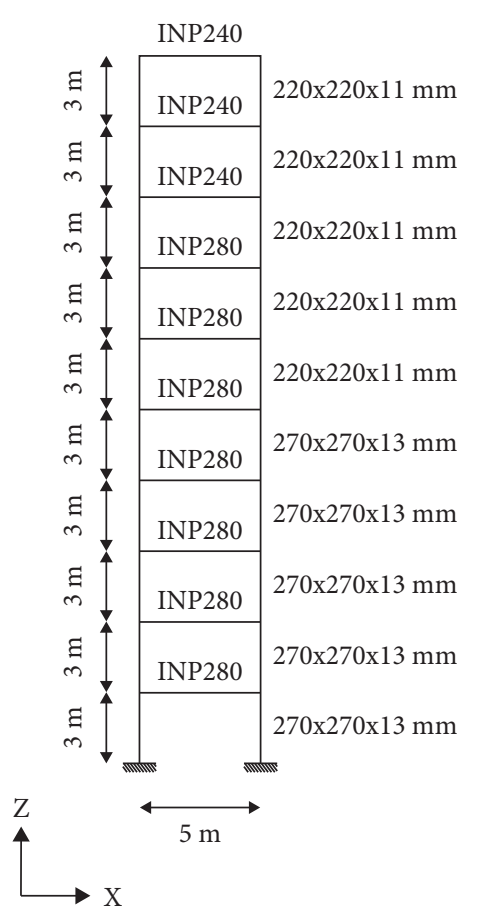

(a)
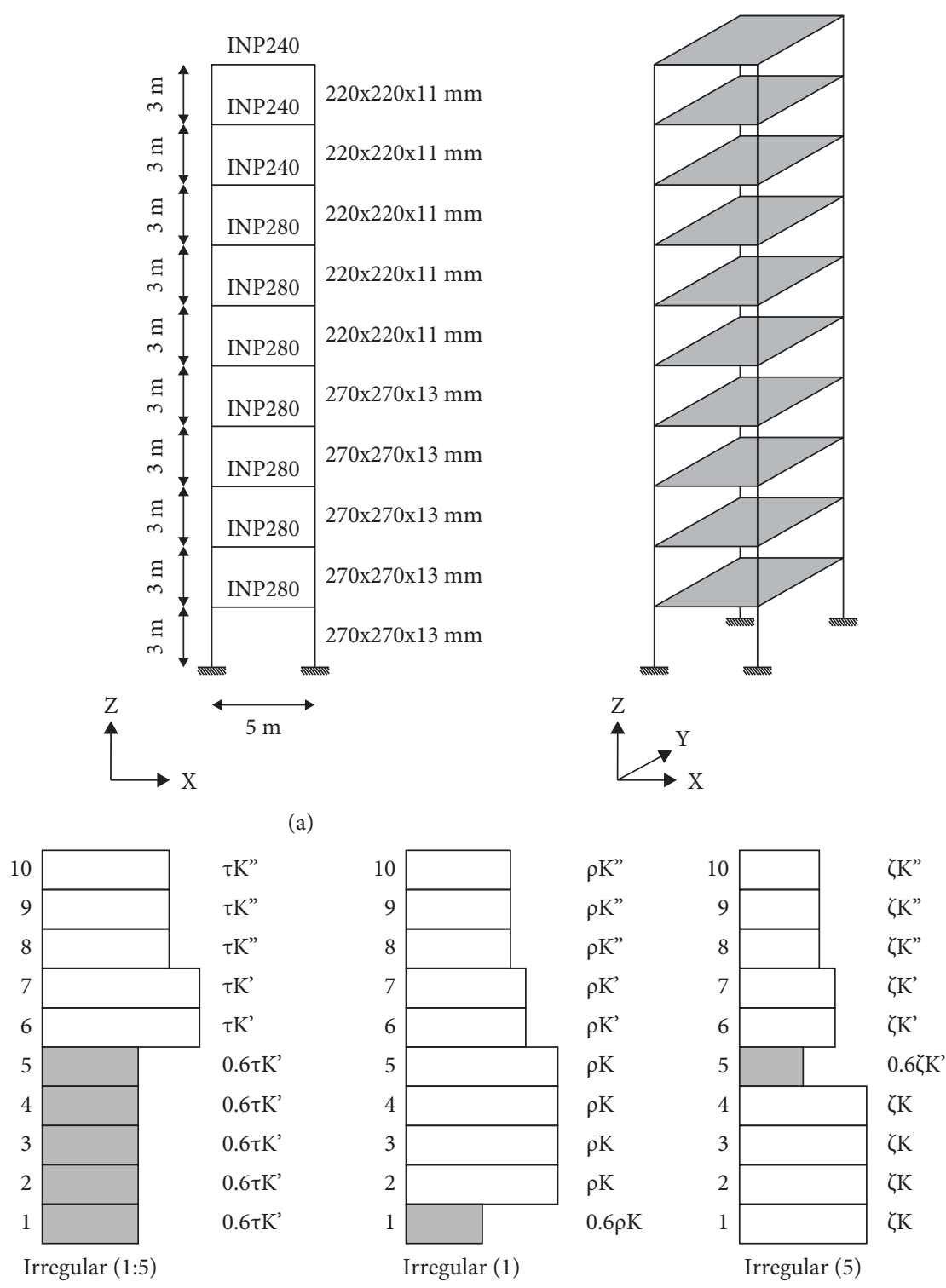

(b)

Figure 1: (a) Plan and elevation view of the regular structure. (b) Structures with vertical stiffness irregularity.

By applying a stiffness irregularity coefficient to certain stories in the regular structures, the stiffness of stories is changed to simulate different cases of nongeometric irregularity. In order to keep the other variables constant and merely study them irregularly, the main characteristics of the regular and irregular structures including the first mode period, stiffness, and yielding base shear are kept constant. The irregularity coefficient is defined according to the following equation [23]:

$$
\mathrm{IF}=\frac{K_{I}}{K_{A}}
$$

where IF is the irregularity coefficient, $K_{\mathrm{I}}$ is the stiffness of the irregular story, and $K_{\mathrm{A}}$ is the stiffness of the adjacent upper floor.
Different states of stiffness irregularity are modeled by applying an irregularity coefficient of $60 \%$ in three different height levels including the lower half of the structure height (stories 1 to 5), the lowest story (first story), and the middle story (story 5) according to Figure 1(b). The nonlinear structural simulation of the frame is carried out in OpenSees software.

\section{Simulation of Passive and Semiactive Dampers}

3.1. Numerical Model of the TMD. The omitted TMD consists of mass, spring, and damper elements. If the stiffness and damping parameters of the TMD are adjusted correctly, it can reduce the vibrations of the main structure due to the 
inertial force generated during the vibration. If the objective of using this damper is to reduce the displacements of the main structure, assuming that the load is harmonic and the main structure is an undamped Single-Degree-Of-Freedom (SDOF) system, the optimal parameters can be derived from the following equations (2) and (3) [24].

$$
\begin{aligned}
& \alpha_{\mathrm{opt}}=\frac{1}{1+\bar{m}}, \\
& \xi_{\mathrm{opt}}=\sqrt{\frac{3 \bar{m}}{8(1+\bar{m})}},
\end{aligned}
$$

where $\alpha_{\text {opt }}$ represents the optimal ratio of TMD frequency to the frequency of the SDOF system. $\bar{m}$ is the ratio of the mass of TMD to the overall mass of the structure. $\xi_{\text {opt }}$ denotes the optimal damping ratio of the TMD. Assuming the desired mass ratio, the TMD mass is obtained and by calculating the optimal frequency ratio, the TMD spring stiffness can be calculated. For structures with damping, equations (2) and (3) are modified as follows [25]:

$$
\begin{aligned}
& \bar{\alpha}_{\text {opt }}=\alpha_{\text {opt }}-\left(0.241+1.7 \bar{m}-2.6 \bar{m}^{2}\right) \xi_{s}-\left(1-1.9 \bar{m}+\bar{m}^{2}\right) \xi_{s}^{2} \\
& \bar{\xi}_{\text {opt }}=\xi_{\text {opt }}+\left(0.13+0.12 \bar{m}+0.4 \bar{m}^{2}\right) \xi_{s}-\left(0.01+0.9 \bar{m}+3 \bar{m}^{2}\right) \xi_{s}^{2},
\end{aligned}
$$

where $\xi_{s}$ is the damping ratio of the main structure. In this study, the mass ratio of TMD is assumed to be 0.02 . Since the maximum displacement of this structure occurs at the roof level, this damper is installed at the roof level.

3.2. Numerical Model of the MR Damper and the Fuzzy Control System. In this study, the Bouc-Wen model [26] is used for the MR damper. This model consists of a Bouc-Wen element and a viscous damper in parallel. The properties of the MR damper and the fuzzy controller are such that it is not possible to model them directly by OpenSees software. Therefore, the force corresponding to the damper is calculated by MATLAB software at each step, and the force is applied to the level at which the damper is located, in OpenSees. The connection between OpenSees and MATLAB is rendered through a TCP-IP method.

According to this method, the SDOF system is subjected to one step of dynamic loading. So, the following is true for the SDOF structure.

$$
[M]_{n \times n}\{\ddot{u}\}+[c]_{n \times n}\{\dot{u}\}+[k]_{n \times n}\{u\}=\left\{\begin{array}{c}
F_{1} \\
F_{2} \\
\vdots \\
F_{n}
\end{array}\right\}_{n \times 1} .
$$

Accordingly, the relative velocity at MR damper level is obtained. Relative velocity is used as the input to the designed fuzzy system to determine the appropriate command voltage to the MR damper.

Once the required voltage is determined, the MR damping force is calculated as follows [26].

$$
\begin{aligned}
F_{\mathrm{MRD}} & =C_{0} \dot{x}+\alpha z, \\
\dot{z} & =-\gamma|\dot{x}| z|\dot{z}|^{s-1}-\beta \dot{x}|z|^{s}+A_{m} \dot{x},
\end{aligned}
$$

where $F_{\mathrm{MRD}}$ is the damping force corresponding to the MR device, and $x$ is the damper displacement. $s, \gamma, \beta$, and $A_{m}$ are constant values (Table 1 ). $z$ represents the evolutionary variable obtained through equation (8) and can also be determined using equations (9) and (10) [26]:

$$
\begin{gathered}
\alpha=\alpha(u)=\alpha_{a}+\alpha_{b} u, \\
C_{0}=C_{0}(u)=C_{0 a}+C_{0 b} u,
\end{gathered}
$$

where the command voltage is denoted by $u . \alpha_{a}, \alpha_{b}, C_{0 a}$, and $C_{0 b}$ are constant values presented in Table 1 [27].

Once the equivalent force of the MR damper is calculated through (6), the force is applied to the level at which the damper is installed (i.e., between the bottom and top floors at the first story) and the force term in equation (6) changes as follows:

$$
\left\{\begin{array}{c}
F_{1}+F_{\mathrm{MRD}} \\
F_{2} \\
\vdots \\
F_{n}
\end{array}\right\}_{n \times 1} .
$$

One of the disadvantages of semiactive and active devices is the time delay, which reduces the efficiency depending on the time required to execute the command. This time in the MR damper is very short (between 0.02 and $0.1 \mathrm{~s}$ ). Due to the operating mechanism of these dampers, the command voltage is not applied immediately. To simulate the time lag between the applied voltage and the command voltage, equation (12) is employed [26].

$$
\dot{u}=-\eta(u-v)
$$

where $\eta$ is the constant value presented in Table 1 and $v$ is the command voltage. Equation (12) can also be rewritten as follows:

$$
\frac{\mathrm{d} u}{\mathrm{~d} t}=\eta v-\eta u
$$

Multiplying the equation by $\mathrm{d} t$ and rewriting $\mathrm{d} u$ as the difference between the two consecutive values, equation (14) is derived.

$$
u_{i}-u_{i-1}=\eta v \mathrm{~d} t-\eta u_{i} \mathrm{~d} t
$$

Therefore, by placing each step on the sides of the equation (14), the voltage response applied to the $i$-th step is equal to

$$
\begin{aligned}
u_{i}+\eta u_{i} \mathrm{~d} t & =\eta v \mathrm{~d} t+u_{i-1} \\
u_{i} & =\frac{\eta v \mathrm{~d} t+u_{i-1}}{1+\eta \mathrm{d} t} .
\end{aligned}
$$


TABLe 1: Parameters used for MR damper model.

\begin{tabular}{lccccc}
\hline Parameter & Value & Parameter & Value & Parameter & Value \\
\hline$\alpha_{a}$ & $1.0872 \times 10^{7}(\mathrm{~N} / \mathrm{m})$ & $C_{0 b}$ & $4400(\mathrm{Ns} / \mathrm{m} / \mathrm{V})$ & $\beta$ & $300\left(\mathrm{~m}^{-1}\right)$ \\
$\alpha_{b}$ & $4.9616 \times 10^{7}(\mathrm{~N} / \mathrm{m} / \mathrm{V})$ & $A_{m}$ & 1.2 & $\gamma$ & $300\left(\mathrm{~m}^{-1}\right)$ \\
$C_{0 a}$ & $440(\mathrm{Ns} / \mathrm{m})$ & $s$ & 1 & $\eta$ & $50\left(\mathrm{~s}^{-1}\right)$ \\
\hline
\end{tabular}

The values for $\alpha$ and $C_{0}$ in each step are also obtained according to the following equations (16) and (17):

$$
\begin{gathered}
\alpha_{i}=\alpha_{a}+\alpha_{b} u_{i}, \\
C_{0_{i}}=C_{0_{a}}+C_{0_{b}} u_{i} .
\end{gathered}
$$

Equation (8) can be rewritten as follows:

$$
\begin{aligned}
\dot{z} & =\frac{\mathrm{d} z}{\mathrm{~d} t}=\left(-\gamma|\dot{x}| z|\dot{z}|^{n-1}-\beta \dot{x}|z|^{n}+A_{m} \dot{x}\right) \\
z_{i}-z_{i-1} & =\left(-\gamma|\dot{x}| z|\dot{z}|^{n-1}-\beta \dot{x}|z|^{n}+A_{m} \dot{x}\right) \mathrm{d} t .
\end{aligned}
$$

Considering $s=1$, equation (17) is equal to

$$
z_{i}+\gamma|\dot{x}| z_{i} \mathrm{~d} t+\beta \dot{x}\left|z_{i}\right| \mathrm{d} t=A_{m} \dot{x} \mathrm{~d} t+z_{i-1} .
$$

Accordingly, $z$ is obtained as follows:

$$
\begin{aligned}
& \text { if } z_{i} \geq 0 \Rightarrow z_{i}=\frac{A_{m} \dot{x} \mathrm{~d} t+z_{i-1}}{1+\gamma|\dot{x}| \mathrm{d} t+\beta \dot{x} \mathrm{~d} t} \\
& \text { if } z_{i}<0 \Rightarrow z_{i}=\frac{A_{m} \dot{x} \mathrm{~d} t+z_{i-1}}{1+\gamma|\dot{x}| \mathrm{d} t-\beta \dot{x} \mathrm{~d} t} .
\end{aligned}
$$

At the end of each step, $u_{i}$ and $z_{i}$ values are assigned to $u_{i-1}$ and $z_{i-1}$ in the next step.

$$
u_{i-1}=u_{i} \text { and } z_{i-1}=z_{i}
$$

According to the presented equations, the MR damper model is verified, and the corresponding results are shown in Figure 2(a).

Nowadays, many semiactive control algorithms such as Sky-Hook, Ground-Hook, and Lyapunov have been proposed for structural control purposes [28]. These classical algorithms consider the minimum and maximum values of the output variable, while the change from minimum to maximum or vice versa cannot be done instantly. On the other hand, a sudden change in voltage, which results in a sudden variation of the damping force, can cause local damage to the structure. With the changes made by the researchers in these algorithms, the in-between values were also achieved. However, these in-between values were obtained without considering the nonlinear effects in the structure. Fuzzy control algorithm was used by researchers to determine the output continuously between the minimum and maximum values and with the ability to factor in the uncertainties, complexities, and nonlinear effects. In this study, a fuzzy control algorithm is used to determine the input voltage of the MR damper.

The input values, i.e., the relative velocity across the damper, are fuzzified through membership functions. A set of fuzzy if-then rules in terms of fuzzy variables is provided.
Accordingly, the fuzzy inputs are evaluated based on the fuzzy rules to obtain the fuzzy output variable. Since the fuzzy inference system must ultimately determine the numerical value of MR damper command voltage, in the final stage, the defuzzification procedure is applied to convert the fuzzy variables into numerical variables. In this study, the voltage, in the range of 0 to $10 \mathrm{~V}$, is determined based on the relative velocity across the damper recorded by the sensors. Considering this voltage range, a maximum damping force of $1000 \mathrm{kN}$ can be provided.

As shown in Figures 2(b) and 2(c), the designed fuzzy system consists of 9 triangular and 2 Gaussian membership functions for the input variable, and 6 triangular membership functions for the output variable.

The fuzzy rule table and the definition of the linguistic variables are presented in Table 2. It is observed in the fuzzy rules that the voltage is chosen in such a way that the structure remains in equilibrium. The structure has the highest velocity at the moment of approaching the equilibrium state or getting out of the equilibrium state. Therefore, it is necessary to use the maximum capacity of the MR damper to keep the structure in the equilibrium state. Accordingly, the voltage at different relative velocities is determined by the fuzzy system.

3.3. Earthquake Records Applied to the Structure. In this study, in order to investigate the performance of different control strategies in vibration mitigation of the structure, 7 far-field and 7 near-field accelerograms are used as excitation records. The characteristics of the earthquake records are presented in Table 3. Before performing the time history analysis, the accelerograms are required to be scaled in accordance with the design codes. In the present study, the scaling is performed based on the Peak Ground Acceleration (PGA), and incremental dynamic analysis is performed with PGA values ranging from 0.1 to $1.0 \mathrm{~g}$ with a step of $0.1 \mathrm{~g}$.

To perform the comparative study, the displacement and acceleration response of all floors as well as the base shear and base moment of the structure are examined in both controlled and uncontrolled states. For this purpose, 8 performance criteria are used, 4 of which are related to the maximum responses, and the other 4 are related to the root mean square of the responses. The mathematical description of the performance criteria is presented in Table 4 . In the presented formulations, $x, \ddot{x}, V$, and $M$ respectively represent the displacement, acceleration, base shear, and base moment of the structure. NS is the number of stories. $u$ and $c$ subscripts refer to uncontrolled and controlled structures. For $J_{5}$ to $J_{8},\|\cdot\|$ represents the norm of the structural responses, which is calculated according to the following equation: 


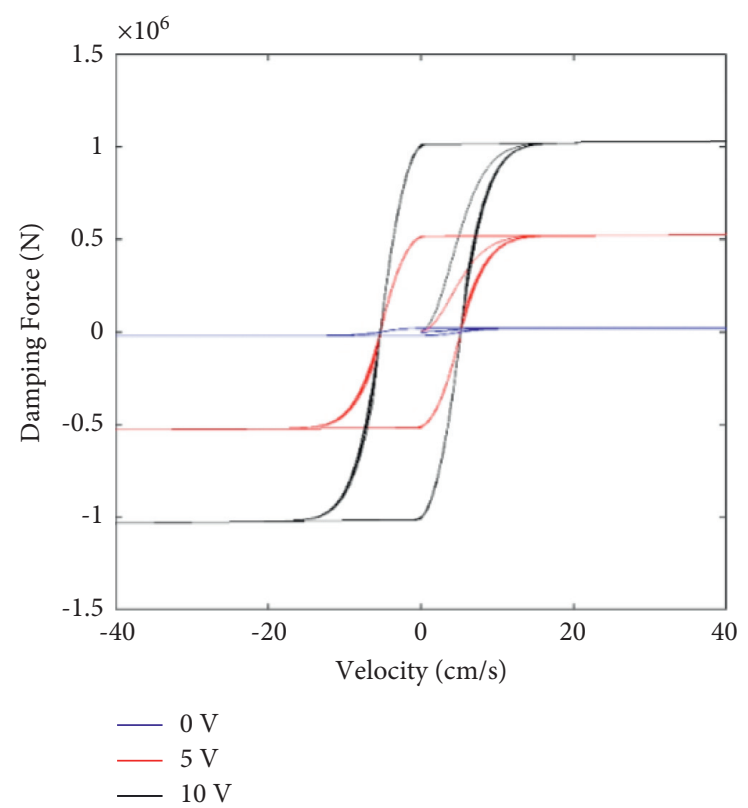

(a)

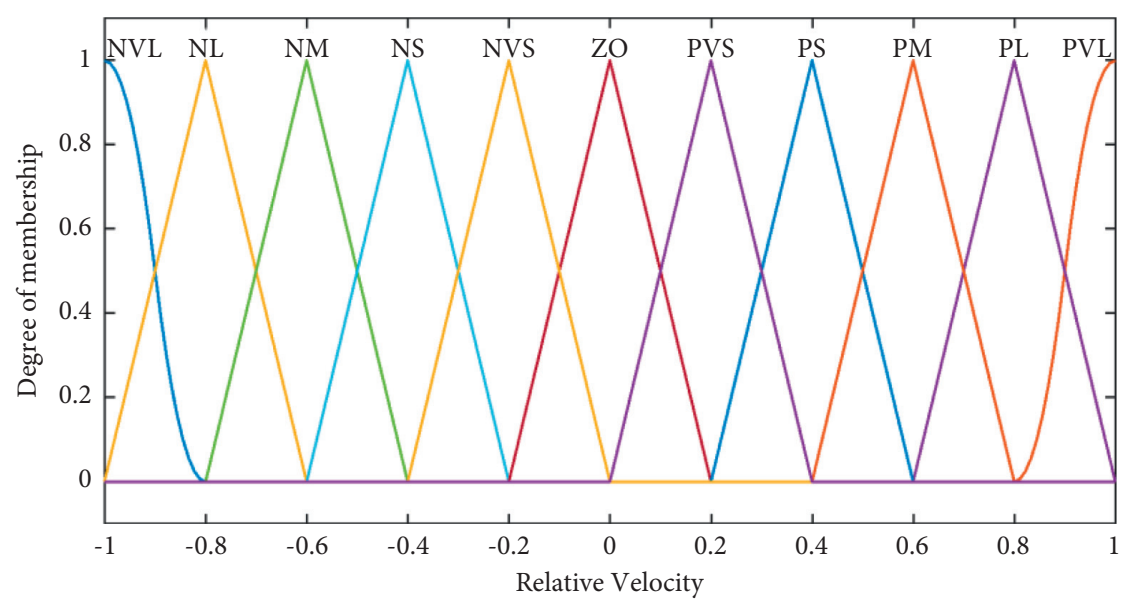

(b)

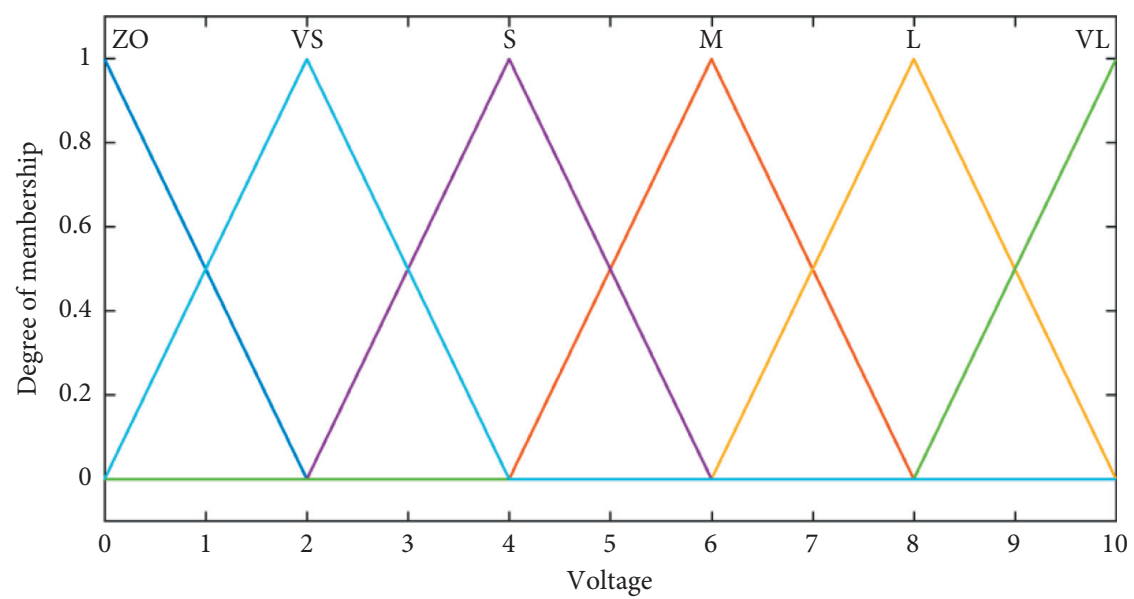

(c)

Figure 2: (a) The behavior of the MR damper model simulated in the present study, (b) membership functions for input variable (relative velocity), (c) membership functions for output variable (voltage). 
TABle 2: Fuzzy rule table and linguistic variables.

\begin{tabular}{ccccccccccc}
\hline \multicolumn{10}{c}{ Relative velocity } \\
\hline Voltage & NVL & NL & NM & NS & NVS & ZO & PVS & PS & PM & PL \\
\hline
\end{tabular}

$(\mathrm{N}, \mathrm{P}) \mathrm{V}$ : -(negative, positive) very large; $(\mathrm{N}, \mathrm{P}) \mathrm{L}$ : (negative, positive) large; $(\mathrm{N}, \mathrm{P}) \mathrm{M}$ : (negative, positive) medium; $(\mathrm{N}, \mathrm{P}) \mathrm{S}$ : (negative, positive) small; $(\mathrm{N}, \mathrm{P}) \mathrm{V}$ : -(negative, positive) very small; $\mathrm{Z}:$-zero.

TABLE 3: Characteristics of earthquakes.

\begin{tabular}{|c|c|c|c|}
\hline \multicolumn{4}{|c|}{ Far-filed Earthquakes } \\
\hline No. & Name & Station & PGA (g) \\
\hline 1 & Northridge & Beverly hill & 0.52 \\
\hline 2 & Northridge & CanyonCountry- & 0.48 \\
\hline 3 & Duzce, Turkey & Bolu & 0.82 \\
\hline 4 & Hector mine & Hector & 0.34 \\
\hline 5 & Imperial valley & Delta & 0.35 \\
\hline 6 & Imperial valley & El Centro array & 0.38 \\
\hline 7 & Kobe, Japan & Nishi-Akashi & 0.51 \\
\hline \multicolumn{4}{|c|}{ Near-filed earthquakes } \\
\hline No. & Name & Station & PGA (g) \\
\hline 1 & Imperial Valley-06 & El Centro array \#6 & 0.44 \\
\hline 2 & Imperial Valley-06 & El Centro array \#7 & 0.46 \\
\hline 3 & Irpinia, Italy-01 & Sturno & 0.31 \\
\hline 4 & Superstition Hills-02 & Parachute test site & 0.42 \\
\hline 5 & Loma Prieta & Saratoga-Aloha & 0.38 \\
\hline 6 & Erzican, Turkey & Erzincan & 0.49 \\
\hline 7 & Cape Mendocino & Petrolia & 0.63 \\
\hline
\end{tabular}

TABle 4: Definition of the performance criteria.

\section{Criteria}

$J_{1}=\sum_{i=1}^{N S} \max \left|x_{c}(t)\right| / \sum_{i=1}^{N S} \max \left|x_{u}(t)\right|$

$J_{2}=\sum_{i=1}^{N \bar{N} S} \max \left|\ddot{x}_{c}(t)\right| / \sum_{i=1}^{N} \max \left|\ddot{x}_{u}(t)\right|$

$J_{3}=\max \left|V_{c}(t)\right| / \max \left|V_{u}(t)\right|$

$J_{4}=\max \left|M_{c}(t)\right| / \max \left|M_{u}(t)\right|$

$J_{5}=\sum_{i=1}^{N S} \max \left\|x_{c}(t)\right\| / \sum_{i=1}^{N S} \max \left\|x_{u}(t)\right\|$

$J_{6}=\sum_{i=1}^{N \bar{N} S} \max \left\|\ddot{x}_{c}(t)\right\| / \sum_{i=1}^{N \bar{N} S} \max \left\|\ddot{x}_{u}(t)\right\|$

$J_{7}=\max \left\|V_{c}(t)\right\| / \max \left\|V_{u}(t)\right\|$

$J_{8}=\max \left\|M_{c}(t)\right\| / \max \left\|M_{u}(t)\right\|$

$$
\|\cdot\|=\sqrt{\frac{1}{t_{f}} \int_{0}^{t_{f}}(\cdot)^{2} \mathrm{~d} t}
$$

where $t_{f}$ is the analysis duration $[19,27]$.

Figures 3(a)-3(d) show the residual displacements of the floors for the uncontrolled structure as well as the structures controlled by the proposed strategies, under far-field earthquakes with a GPA of $0.5 \mathrm{~g}$. In these figures, 7 plots corresponding to earthquakes 1 to 7 , according to Table 3 respectively from left to right, are presented. It is observed that the residual displacement of the first floor is almost negligible in the structures controlled by the MR damper or the combined MR-TMD system. On the other hand, in the uncontrolled structure or in the structure controlled by the TMD, the residual displacement is noticeable in the first floor. This is due to the placement of the MR damper at the first story, which allows direct control of the first floor displacement.
Figures 4(a)-4(d) show the residual displacements of the floors for the uncontrolled structure as well the structures with different control strategies, under near-field earthquakes. In these figures, 7 plots corresponding to earthquakes 1 to 7 , according to Table 3 respectively from left to right, are presented. Similar to far-field earthquake results, the control system with MR damper and the combined MRTMD system lead to very small residual displacements in the first floor due to the placement of MR dampers at the first story.

Table 5 presents the average displacement of the residual displacements of all floors for the studied earthquakes. In order to study more closely, the difference between the minimum and maximum residual displacements in each structure is divided into 4 intervals, respectively, displayed in orange, yellow, light green, and dark green to determine the performance of each strategy. According to the results for far-field earthquakes, the MR dampers can only perform better than the last quartile in the regular structure and in the irregular structure with reduced stiffness in the first floor, which is not a remarkable performance, while the passive TMD shows better performance for far-field earthquakes and improves the performance of the regular structure and the irregular structure in the $1^{\text {st }}-5^{\text {th }}$ stories to the first rank, the irregular structure in the $1^{\text {st }}$ story to the third rank, and irregular structure in the $5^{\text {th }}$ story to the third rank. In the combined MR-TMD system, the greatest reductions in the residual displacement for all structures are observed, which indicates the compensation of the weaknesses of each device and improved robustness of the control system. In near-field 

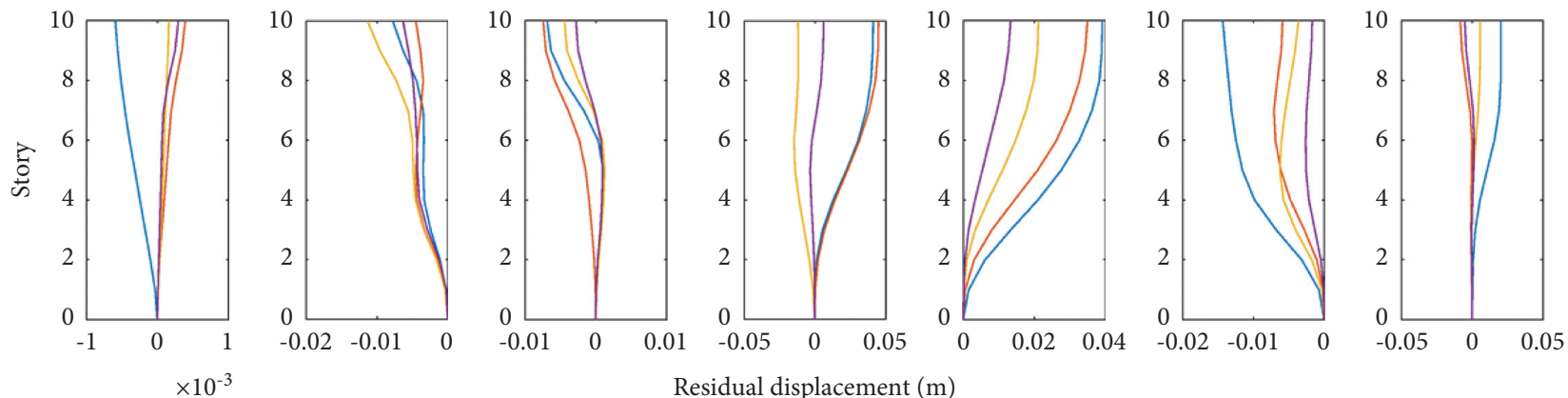

— Uncontrolled

- MR

— TMD

— MR+TMD

(a)
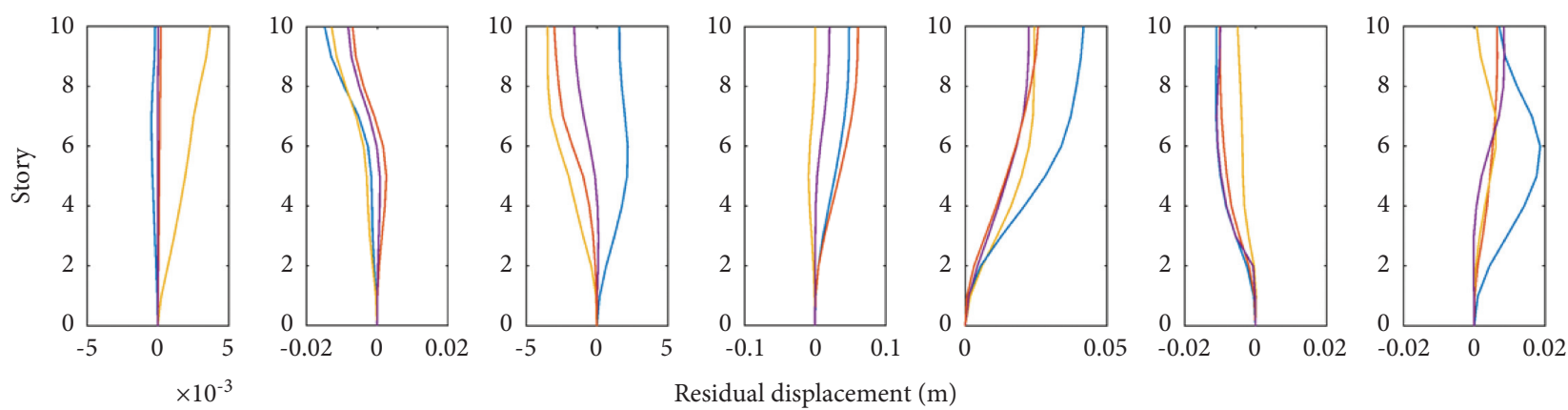

Residual displacement (m)

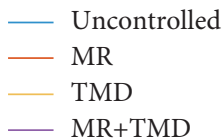

\section{- MR+TMD}

(b)
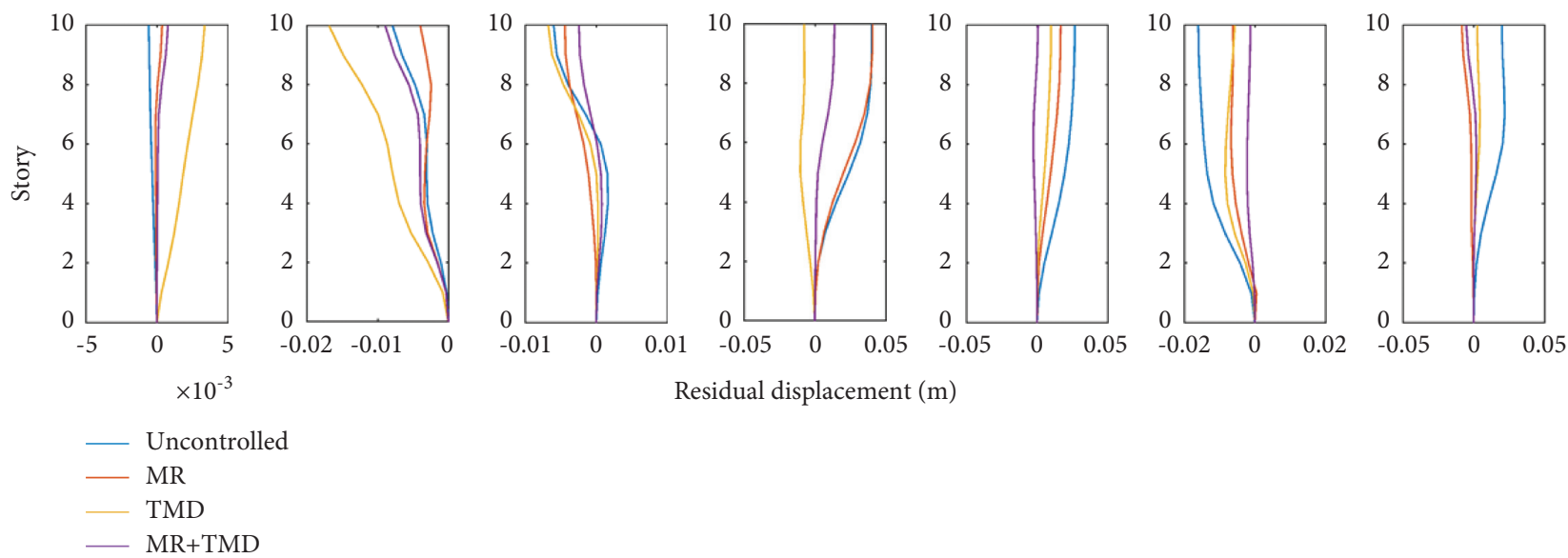

(c)

Figure 3: Continued. 

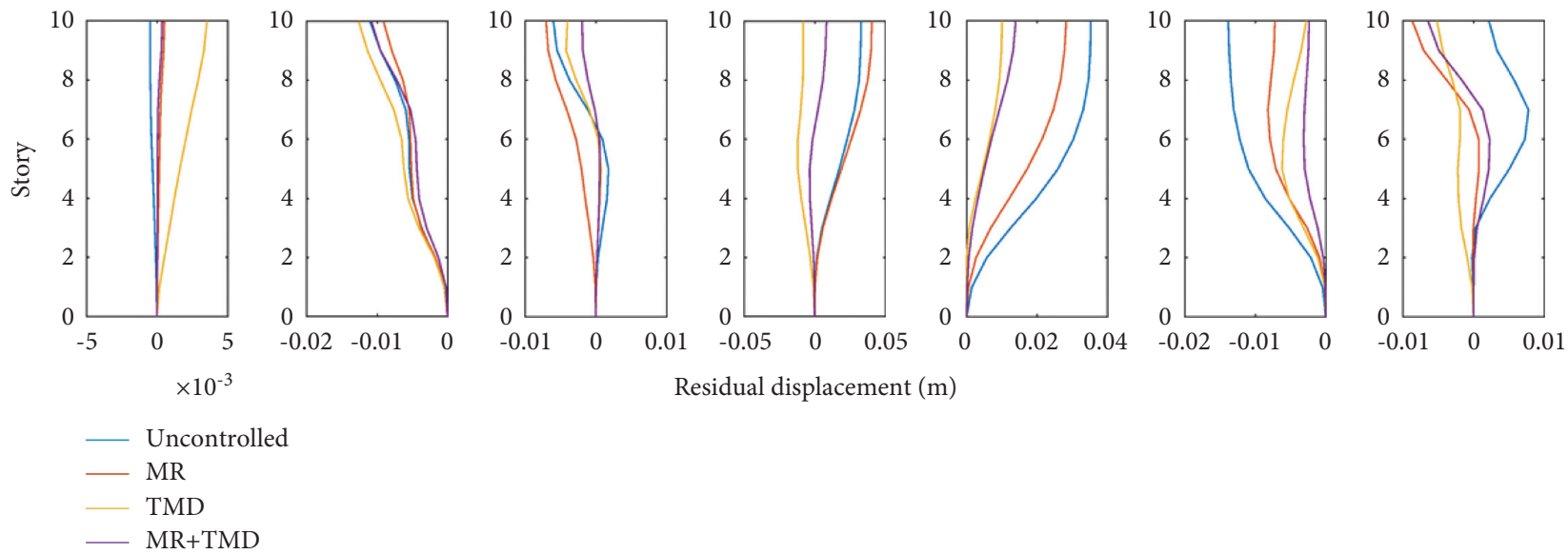

(d)

FIGURE 3: Residual displacement of different floors under far-filed earthquakes in: (a) regular structure, (b) irregular structure with reduced stiffness in the 1st-5th stories, (c) irregular structure with reduced stiffness in the 1st story, (d) irregular structure with reduced stiffness in the 5 th story.
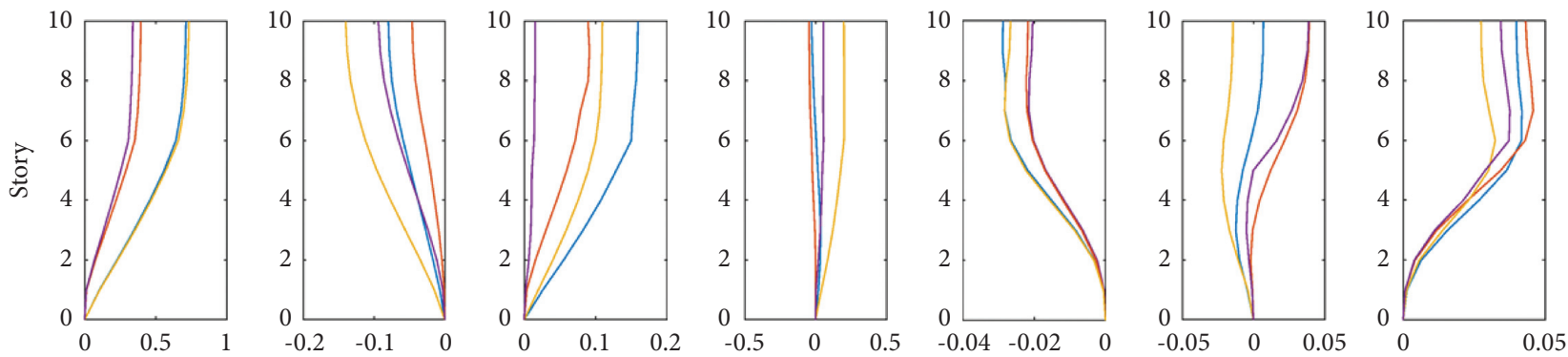

Residual displacement (m)
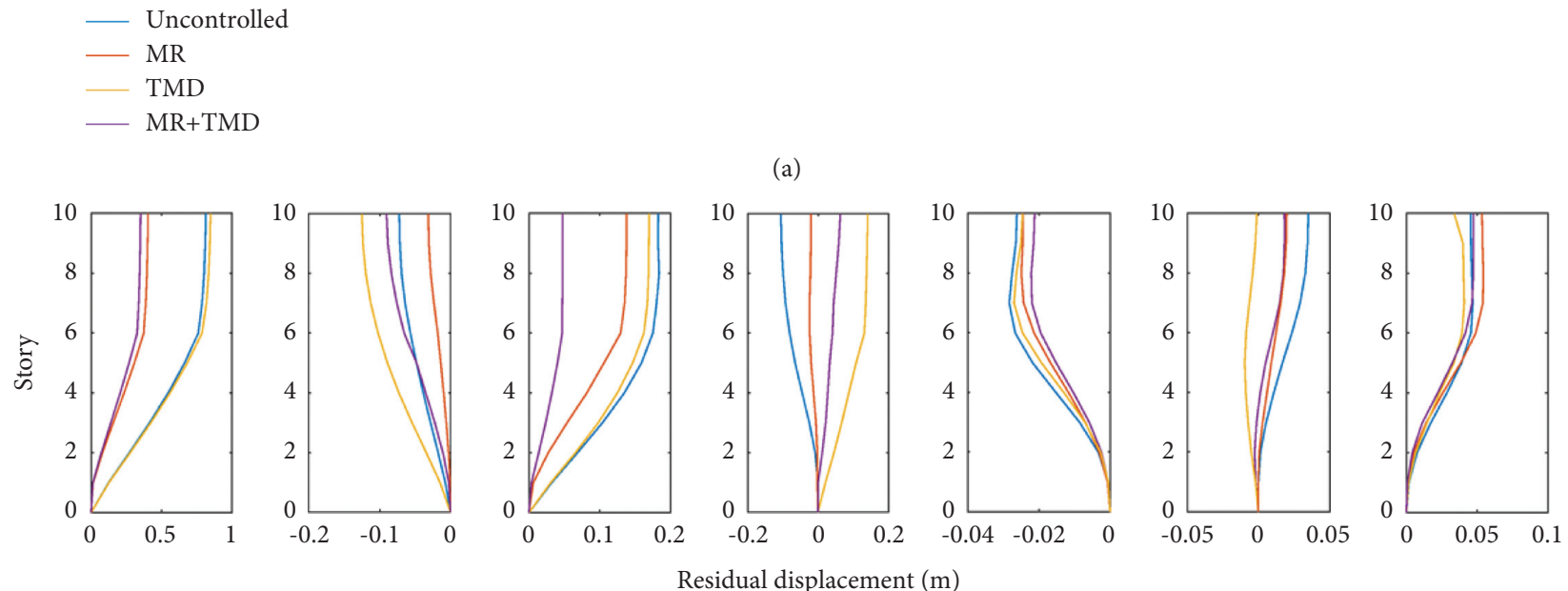

Residual displacement (m)

Uncontrolled

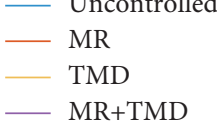

(b)

Figure 4: Continued. 

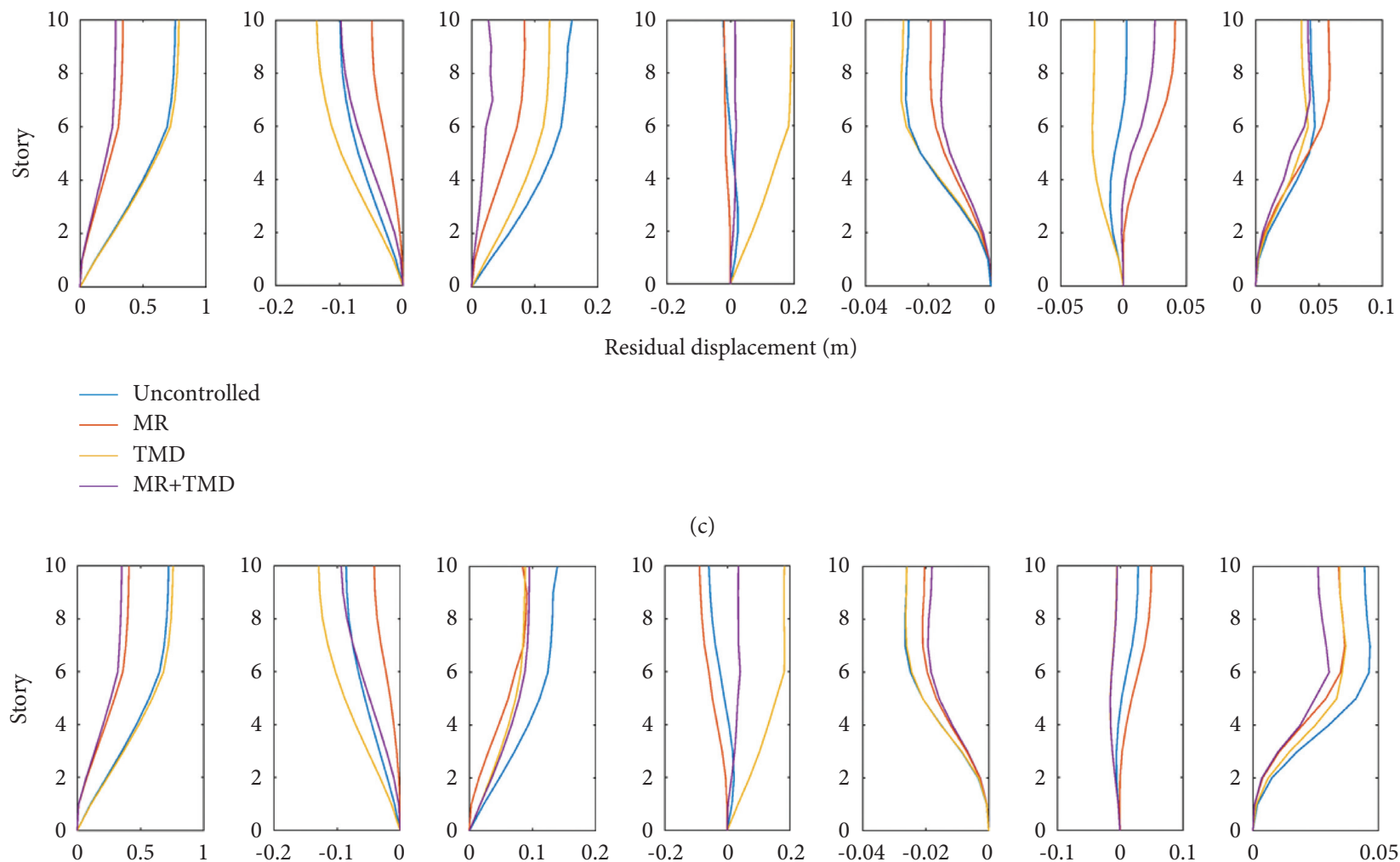

(c)
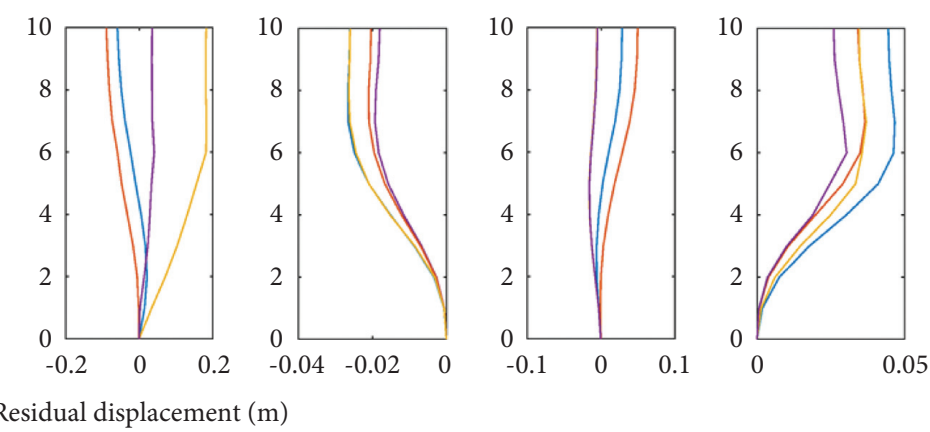

_ Uncontrolled
- MR
TMD
— MR+TMD

Residual displacement $(\mathrm{m})$

(d)

FIGURE 4: Residual displacement of different floors under near-filed earthquakes in: (a) regular structure, (b) irregular structure with reduced stiffness in the 1st-5th stories, (c) irregular structure with reduced stiffness in the 1st story, (d) irregular structure with reduced stiffness in the 5 th story.

TABle 5: Average residual displacements under near- and far-field earthquakes for different control strategies.

\begin{tabular}{|c|c|c|c|c|c|c|c|c|}
\hline \multirow{3}{*}{ Control strategy } & \multicolumn{8}{|c|}{ Residual displacement (mm) } \\
\hline & \multicolumn{4}{|c|}{ Far-field } & \multicolumn{4}{|c|}{ Near-field } \\
\hline & $R$ & $I 1-5$ & $I 1$ & $I 5$ & $R$ & $I 1-5$ & $I 1$ & $I-5$ \\
\hline Uncontrolled & 0.0058 & 0.0070 & 0.0051 & 0.0037 & 0.0775 & 0.0864 & 0.0799 & 0.0747 \\
\hline MR & 0.0042 & 0.0058 & 0.0026 & 0.0030 & 0.0399 & 0.0477 & 0.0381 & 0.0385 \\
\hline TMD & 0.0008 & 0.0009 & 0.0018 & 0.0019 & 0.0861 & 0.1006 & 0.0916 & 0.0867 \\
\hline $\mathrm{MR}+\mathrm{TMD}$ & 0.0001 & 0.0022 & 0.0002 & $2.0 e-5$ & 0.0330 & 0.0373 & 0.0257 & 0.0371 \\
\hline
\end{tabular}

earthquakes, due to a sharp acceleration peak in the ground motion record, the required time for the TMD to generate desirable inertial force to control the vibrations of the structure is not provided. Therefore, it leads to larger residual displacements compared with the uncontrolled state. However, by using a semiactive control strategy, the effect of the record type is eliminated, and the residual displacements in the structures are reduced effectively.

The averaged performance criteria for the regular and irregular structures subjected to far-field earthquakes are presented in Tables 6-9, and the corresponding results related to near-field earthquakes are presented in Tables 10-13
$J_{1}$ evaluates the efficiency of control systems to reduce the displacement of the structure. A reduction in $J_{1}$ indicates the improved performance of the control system in protecting the stability of the structure. Comparing the presented performance criteria reveals that the control system consisting of MR damper has a more stable trend for different PGAs, while the efficiency of the TMD decreases with the increase in PGA. The simultaneous use of MR dampers and TMD in the control system makes it perform better for all cases compared with MR damper and TMD alone. However, due to the presence of TMD damper in this system, the performance decreases while increasing the PGA, and there 
TAвLE 6: Performance criteria for the proposed control systems under far-field earthquakes: regular structure.

\begin{tabular}{|c|c|c|c|c|c|c|c|c|c|c|c|}
\hline & \multicolumn{10}{|c|}{ PGA (g) } \\
\hline & & 0.1 & 0.2 & 0.3 & 0.4 & 0.5 & 0.6 & 0.7 & 0.8 & 0.9 & 1.0 \\
\hline \multirow{3}{*}{$J_{1}$} & MR & 0.9248 & 0.8925 & 0.8738 & 0.8864 & 0.8983 & 0.9067 & 0.8922 & 0.8795 & 0.8899 & 0.8990 \\
\hline & TMD & 0.8438 & 0.8455 & 0.8617 & 0.8989 & 0.9194 & 0.9487 & 0.9665 & 0.9701 & 0.9585 & 0.9445 \\
\hline & $\mathrm{MR}+\mathrm{TMD}$ & 0.7465 & 0.7418 & 0.7578 & 0.8035 & 0.8309 & 0.8532 & 0.8588 & 0.8673 & 0.8688 & 0.8641 \\
\hline \multirow{3}{*}{$J_{2}$} & MR & 1.0196 & 1.0091 & 1.0024 & 0.9950 & 0.9964 & 0.9937 & 0.9978 & 1.0003 & 0.9974 & 0.9925 \\
\hline & TMD & 0.9804 & 0.9827 & 0.9902 & 0.9987 & 1.0053 & 1.0015 & 1.0017 & 1.0003 & 0.9982 & 0.9971 \\
\hline & $\mathrm{MR}+\mathrm{TMD}$ & 0.9870 & 0.9821 & 0.9882 & 0.9915 & 0.9975 & 0.9974 & 1.0003 & 1.0013 & 0.9971 & 0.9901 \\
\hline \multirow{3}{*}{$J_{3}$} & MR & 0.2417 & 0.2703 & 0.3123 & 0.3276 & 0.3504 & 0.3797 & 0.4016 & 0.4189 & 0.4279 & 0.4158 \\
\hline & TMD & 0.8812 & 0.8865 & 0.9354 & 0.9746 & 0.9879 & 0.9897 & 0.9911 & 0.9899 & 0.9953 & 0.9865 \\
\hline & MR + TMD & 0.2192 & 0.2229 & 0.2750 & 0.2982 & 0.3328 & 0.3694 & 0.3950 & 0.4112 & 0.4180 & 0.4152 \\
\hline \multirow{3}{*}{$J_{4}$} & MR & 0.2738 & 0.3131 & 0.3447 & 0.3603 & 0.3836 & 0.3982 & 0.4121 & 0.4208 & 0.4372 & 0.4573 \\
\hline & TMD & 0.8887 & 0.8927 & 0.9316 & 0.9449 & 0.9832 & 0.9945 & 0.9909 & 0.9804 & 0.9766 & 0.9724 \\
\hline & $\mathrm{MR}+\mathrm{TMD}$ & 0.2290 & 0.2544 & 0.3007 & 0.3346 & 0.3696 & 0.3891 & 0.4025 & 0.4151 & 0.4281 & 0.4369 \\
\hline \multirow{3}{*}{$J_{5}$} & MR & 0.8642 & 0.8217 & 0.7635 & 0.7729 & 0.8092 & 0.8194 & 0.8061 & 0.8029 & 0.8187 & 0.8217 \\
\hline & TMD & 0.6762 & 0.6820 & 0.6849 & 0.7133 & 0.7610 & 0.7939 & 0.8225 & 0.8269 & 0.8303 & 0.8327 \\
\hline & $\mathrm{MR}+\mathrm{TMD}$ & 0.6027 & 0.5998 & 0.5927 & 0.6202 & 0.6460 & 0.6884 & 0.7021 & 0.7103 & 0.7326 & 0.7400 \\
\hline \multirow{3}{*}{$J_{6}$} & MR & 1.0100 & 0.9819 & 0.9565 & 0.9651 & 0.9805 & 0.9863 & 0.9903 & 0.9926 & 0.9950 & 0.9973 \\
\hline & TMD & 0.9121 & 0.9153 & 0.9244 & 0.9482 & 0.9675 & 0.9730 & 0.9769 & 0.9798 & 0.9830 & 0.9864 \\
\hline & $\mathrm{MR}+\mathrm{TMD}$ & 0.9217 & 0.9134 & 0.9133 & 0.9317 & 0.9343 & 0.9726 & 0.9787 & 0.9819 & 0.9854 & 0.9886 \\
\hline \multirow{3}{*}{$J_{7}$} & MR & 0.1836 & 0.1952 & 0.2117 & 0.2391 & 0.2703 & 0.2947 & 0.3104 & 0.3188 & 0.3232 & 0.3255 \\
\hline & TMD & 0.7075 & 0.7146 & 0.7319 & 0.7687 & 0.8129 & 0.8355 & 0.8483 & 0.8560 & 0.8650 & 0.8726 \\
\hline & $\mathrm{MR}+\mathrm{TMD}$ & 0.1424 & 0.1535 & 0.1768 & 0.2056 & 0.2368 & 0.2685 & 0.2863 & 0.2937 & 0.3003 & 0.3044 \\
\hline \multirow{3}{*}{$J_{8}$} & MR & 0.2140 & 0.2327 & 0.2463 & 0.2741 & 0.3048 & 0.3274 & 0.3469 & 0.3624 & 0.3852 & 0.4111 \\
\hline & TMD & 0.6999 & 0.7067 & 0.7201 & 0.7571 & 0.8018 & 0.8241 & 0.8389 & 0.8436 & 0.8517 & 0.8585 \\
\hline & $\mathrm{MR}+\mathrm{TMD}$ & 0.1538 & 0.1688 & 0.1937 & 0.2240 & 0.2558 & 0.2903 & 0.3125 & 0.3301 & 0.3540 & 0.3775 \\
\hline
\end{tabular}

TABLE 7: Performance criteria for the proposed control systems under far-field earthquakes: reduced stiffness in the $1^{\text {st }}-5^{\text {th }}$ stories.

\begin{tabular}{|c|c|c|c|c|c|c|c|c|c|c|c|}
\hline & \multicolumn{10}{|c|}{ PGA (g) } \\
\hline & & 0.1 & 0.2 & 0.3 & 0.4 & 0.5 & 0.6 & 0.7 & 0.8 & 0.9 & 1.0 \\
\hline \multirow{3}{*}{$J_{1}$} & MR & 0.9127 & 0.8744 & 0.8546 & 0.8488 & 0.9052 & 0.9187 & 0.9326 & 0.9042 & 0.8881 & 0.8889 \\
\hline & TMD & 0.8337 & 0.8360 & 0.8518 & 0.8691 & 0.9055 & 0.9408 & 0.9846 & 0.9931 & 0.9744 & 0.9585 \\
\hline & $\mathrm{MR}+\mathrm{TMD}$ & 0.7474 & 0.7429 & 0.7520 & 0.7771 & 0.8213 & 0.8563 & 0.8835 & 0.8798 & 0.8733 & 0.8661 \\
\hline \multirow{3}{*}{$J_{2}$} & MR & 1.0369 & 1.0222 & 1.0107 & 1.0060 & 1.0107 & 1.0122 & 1.0100 & 1.0100 & 1.0103 & 1.0112 \\
\hline & TMD & 0.9832 & 0.9851 & 0.9891 & 0.9930 & 0.9980 & 0.9997 & 0.9990 & 0.9990 & 0.9985 & 0.9987 \\
\hline & $\mathrm{MR}+\mathrm{TMD}$ & 1.0076 & 1.0035 & 1.0029 & 1.0036 & 1.0114 & 1.0127 & 1.0102 & 1.0093 & 1.0092 & 1.0099 \\
\hline \multirow{3}{*}{$J_{3}$} & MR & 0.2554 & 0.2988 & 0.3331 & 0.3755 & 0.3961 & 0.4137 & 0.4397 & 0.4495 & 0.4500 & 0.4595 \\
\hline & TMD & 0.8851 & 0.8924 & 0.9258 & 0.9724 & 0.9914 & 0.9856 & 1.0016 & 1.0008 & 0.9863 & 0.9807 \\
\hline & $\mathrm{MR}+\mathrm{TMD}$ & 0.2276 & 0.2474 & 0.3009 & 0.3388 & 0.3797 & 0.4113 & 0.4348 & 0.4460 & 0.4476 & 0.4469 \\
\hline \multirow{3}{*}{$J_{4}$} & MR & 0.2436 & 0.2914 & 0.3281 & 0.3638 & 0.4013 & 0.4223 & 0.4313 & 0.4410 & 0.4444 & 0.4559 \\
\hline & TMD & 0.8794 & 0.8855 & 0.9115 & 0.9524 & 0.9879 & 1.0065 & 1.0110 & 1.0011 & 0.9865 & 0.9645 \\
\hline & $\mathrm{MR}+\mathrm{TMD}$ & 0.2028 & 0.2352 & 0.2860 & 0.3241 & 0.3683 & 0.4046 & 0.4142 & 0.4253 & 0.4351 & 0.4420 \\
\hline \multirow{3}{*}{$J_{5}$} & MR & 0.8733 & 0.8104 & 0.7361 & 0.7316 & 0.7832 & 0.8051 & 0.8293 & 0.8274 & 0.8244 & 0.8140 \\
\hline & TMD & 0.7407 & 0.7465 & 0.7456 & 0.7718 & 0.7906 & 0.8787 & 0.9083 & 0.9195 & 0.9183 & 0.9172 \\
\hline & $\mathrm{MR}+\mathrm{TMD}$ & 0.6023 & 0.5976 & 0.5844 & 0.6014 & 0.6720 & 0.6965 & 0.7288 & 0.7443 & 0.7532 & 0.7528 \\
\hline \multirow{3}{*}{$J_{6}$} & MR & 1.0237 & 0.9881 & 0.9552 & 0.9590 & 0.9695 & 0.9785 & 0.9852 & 0.9906 & 0.9942 & 0.9976 \\
\hline & TMD & 1.0115 & 1.0149 & 1.0210 & 1.0451 & 1.0041 & 1.0833 & 1.0900 & 1.0953 & 1.0991 & 1.1027 \\
\hline & $\mathrm{MR}+\mathrm{TMD}$ & 0.9153 & 0.9089 & 0.9059 & 0.9235 & 0.9792 & 0.9641 & 0.9739 & 0.9806 & 0.9851 & 0.9890 \\
\hline \multirow{3}{*}{$J_{7}$} & MR & 0.2183 & 0.2236 & 0.2327 & 0.2594 & 0.2836 & 0.3042 & 0.3194 & 0.3307 & 0.3419 & 0.3488 \\
\hline & TMD & 0.7727 & 0.7799 & 0.7916 & 0.8348 & 0.8381 & 0.9212 & 0.9378 & 0.9491 & 0.9589 & 0.9703 \\
\hline & $\mathrm{MR}+\mathrm{TMD}$ & 0.1640 & 0.1726 & 0.1923 & 0.2196 & 0.2596 & 0.2751 & 0.2905 & 0.3053 & 0.3172 & 0.3274 \\
\hline \multirow{3}{*}{$J_{8}$} & MR & 0.1876 & 0.2098 & 0.2230 & 0.2518 & 0.2833 & 0.3079 & 0.3345 & 0.3519 & 0.3724 & 0.3964 \\
\hline & TMD & 0.7631 & 0.7699 & 0.7779 & 0.8181 & 0.8252 & 0.9084 & 0.9259 & 0.9366 & 0.9427 & 0.9516 \\
\hline & $\mathrm{MR}+\mathrm{TMD}$ & 0.1316 & 0.1509 & 0.1772 & 0.2073 & 0.2512 & 0.2740 & 0.2978 & 0.3212 & 0.3429 & 0.3665 \\
\hline
\end{tabular}


TABLE 8: Performance criteria for the proposed control systems under far-field earthquakes: reduced stiffness in the 1st story.

\begin{tabular}{|c|c|c|c|c|c|c|c|c|c|c|c|}
\hline & \multicolumn{10}{|c|}{ PGA (g) } \\
\hline & & 0.1 & 0.2 & 0.3 & 0.4 & 0.5 & 0.6 & 0.7 & 0.8 & 0.9 & 1.0 \\
\hline \multirow{3}{*}{$J_{1}$} & MR & 0.8599 & 0.8150 & 0.8067 & 0.8394 & 0.8556 & 0.8698 & 0.8534 & 0.8372 & 0.8471 & 0.8646 \\
\hline & TMD & 0.8428 & 0.8449 & 0.8674 & 0.9070 & 0.9236 & 0.9604 & 0.9748 & 0.9730 & 0.9609 & 0.9508 \\
\hline & $\mathrm{MR}+\mathrm{TMD}$ & 0.7225 & 0.7142 & 0.7360 & 0.7750 & 0.8051 & 0.8298 & 0.8286 & 0.8257 & 0.8355 & 0.8409 \\
\hline \multirow{3}{*}{$J_{2}$} & MR & 1.0507 & 1.0391 & 1.0250 & 1.0238 & 1.0205 & 1.0129 & 1.0130 & 1.0133 & 1.0114 & 1.0090 \\
\hline & TMD & 0.9799 & 0.9836 & 0.9893 & 1.0002 & 1.0039 & 0.9997 & 0.9999 & 0.9993 & 0.9977 & 0.9972 \\
\hline & MR + TMD & 1.0125 & 1.0073 & 1.0098 & 1.0170 & 1.0218 & 1.0142 & 1.0136 & 1.0131 & 1.0101 & 1.0072 \\
\hline \multirow{3}{*}{$J_{3}$} & MR & 0.3064 & 0.3152 & 0.3535 & 0.3841 & 0.4215 & 0.4328 & 0.4405 & 0.4468 & 0.4578 & 0.4482 \\
\hline & TMD & 0.8872 & 0.8969 & 0.9496 & 0.9695 & 0.9968 & 0.9913 & 0.9894 & 0.9878 & 0.9942 & 0.9824 \\
\hline & $\mathrm{MR}+\mathrm{TMD}$ & 0.2583 & 0.2720 & 0.3260 & 0.3528 & 0.3936 & 0.4167 & 0.4253 & 0.4387 & 0.4460 & 0.4362 \\
\hline \multirow{3}{*}{$J_{4}$} & MR & 0.1841 & 0.2339 & 0.2774 & 0.3057 & 0.3381 & 0.3572 & 0.3661 & 0.3754 & 0.3920 & 0.4103 \\
\hline & TMD & 0.8802 & 0.8876 & 0.9330 & 0.9606 & 0.9841 & 0.9961 & 0.9851 & 0.9839 & 0.9720 & 0.9724 \\
\hline & $\mathrm{MR}+\mathrm{TMD}$ & 0.1556 & 0.1928 & 0.2451 & 0.2708 & 0.3167 & 0.3399 & 0.3512 & 0.3663 & 0.3853 & 0.3958 \\
\hline \multirow{3}{*}{$J_{5}$} & MR & 0.9067 & 0.8291 & 0.7416 & 0.7466 & 0.7645 & 0.7759 & 0.7620 & 0.7557 & 0.7563 & 0.7764 \\
\hline & TMD & 0.7416 & 0.7500 & 0.7520 & 0.7949 & 0.8268 & 0.8826 & 0.9012 & 0.9080 & 0.9100 & 0.9039 \\
\hline & $\mathrm{MR}+\mathrm{TMD}$ & 0.5911 & 0.5850 & 0.5686 & 0.5974 & 0.6199 & 0.6683 & 0.6730 & 0.6746 & 0.6907 & 0.7167 \\
\hline \multirow{3}{*}{$J_{6}$} & MR & 1.0748 & 1.0249 & 0.9834 & 0.9887 & 0.9937 & 0.9946 & 0.9976 & 1.0119 & 1.0020 & 1.0043 \\
\hline & TMD & 1.0194 & 1.0248 & 1.0349 & 1.0615 & 1.0576 & 1.0864 & 1.0909 & 1.0943 & 1.0979 & 1.1015 \\
\hline & $\mathrm{MR}+\mathrm{TMD}$ & 0.9447 & 0.9342 & 0.9296 & 0.9494 & 0.9450 & 0.9806 & 0.9865 & 0.9905 & 0.9939 & 0.9967 \\
\hline \multirow{3}{*}{$J_{7}$} & MR & 0.2954 & 0.2811 & 0.2706 & 0.2898 & 0.3164 & 0.3370 & 0.3529 & 0.3635 & 0.3677 & 0.3715 \\
\hline & TMD & 0.7752 & 0.7863 & 0.8033 & 0.8485 & 0.8769 & 0.9141 & 0.9261 & 0.9346 & 0.9457 & 0.9547 \\
\hline & $\mathrm{MR}+\mathrm{TMD}$ & 0.2073 & 0.2123 & 0.2246 & 0.2469 & 0.2725 & 0.3021 & 0.3193 & 0.3316 & 0.3400 & 0.3455 \\
\hline \multirow{3}{*}{$J_{8}$} & MR & 0.1406 & 0.1690 & 0.1851 & 0.2171 & 0.2505 & 0.2783 & 0.3025 & 0.3211 & 0.3368 & 0.3633 \\
\hline & TMD & 0.7666 & 0.7768 & 0.7897 & 0.8358 & 0.8661 & 0.9044 & 0.9182 & 0.9266 & 0.9341 & 0.9392 \\
\hline & $\mathrm{MR}+\mathrm{TMD}$ & 0.0973 & 0.1205 & 0.1487 & 0.1808 & 0.2123 & 0.2462 & 0.2703 & 0.2894 & 0.3102 & 0.3346 \\
\hline
\end{tabular}

TABle 9: Performance criteria for the proposed control systems under far-field earthquakes: reduced stiffness in the $5^{\text {th }}$ story.

\begin{tabular}{|c|c|c|c|c|c|c|c|c|c|c|c|}
\hline & \multicolumn{10}{|c|}{ PGA (g) } \\
\hline & & 0.1 & 0.2 & 0.3 & 0.4 & 0.5 & 0.6 & 0.7 & 0.8 & 0.9 & 1.0 \\
\hline \multirow{3}{*}{$J_{1}$} & MR & 0.9324 & 0.9010 & 0.8892 & 0.9009 & 0.9095 & 0.9208 & 0.9103 & 0.8957 & 0.9007 & 0.9074 \\
\hline & TMD & 0.8425 & 0.8435 & 0.8597 & 0.8938 & 0.9112 & 0.9461 & 0.9726 & 0.9772 & 0.9640 & 0.9518 \\
\hline & $\mathrm{MR}+\mathrm{TMD}$ & 0.7541 & 0.7486 & 0.7647 & 0.8056 & 0.8377 & 0.8661 & 0.8801 & 0.8811 & 0.8835 & 0.8773 \\
\hline \multirow{3}{*}{$J_{2}$} & MR & 1.0147 & 1.0048 & 0.9975 & 0.9887 & 0.9897 & 0.9876 & 0.9886 & 0.9909 & 0.9915 & 0.9903 \\
\hline & TMD & 0.9824 & 0.9847 & 0.9918 & 0.9998 & 1.0037 & 1.0011 & 1.0005 & 0.9998 & 0.9991 & 0.9989 \\
\hline & $\mathrm{MR}+\mathrm{TMD}$ & 0.9836 & 0.9784 & 0.9829 & 0.9869 & 0.9920 & 0.9906 & 0.9899 & 0.9909 & 0.9897 & 0.9895 \\
\hline \multirow{3}{*}{$J_{3}$} & MR & 0.2229 & 0.2528 & 0.2950 & 0.3208 & 0.3472 & 0.3745 & 0.3986 & 0.4207 & 0.4258 & 0.4195 \\
\hline & TMD & 0.9042 & 0.9099 & 0.9593 & 0.9792 & 1.0048 & 1.0108 & 1.0157 & 1.0028 & 0.9954 & 0.9833 \\
\hline & $\mathrm{MR}+\mathrm{TMD}$ & 0.2101 & 0.2146 & 0.2596 & 0.2869 & 0.3305 & 0.3614 & 0.3918 & 0.4111 & 0.4174 & 0.4097 \\
\hline \multirow{3}{*}{$J_{4}$} & MR & 0.2838 & 0.3299 & 0.3695 & 0.3833 & 0.4049 & 0.4290 & 0.4379 & 0.4451 & 0.4583 & 0.4820 \\
\hline & TMD & 0.9080 & 0.9126 & 0.9582 & 0.9649 & 0.9883 & 1.0246 & 1.0135 & 0.9944 & 0.9794 & 0.9791 \\
\hline & $\mathrm{MR}+\mathrm{TMD}$ & 0.2511 & 0.2798 & 0.3240 & 0.3488 & 0.3901 & 0.4163 & 0.4245 & 0.4345 & 0.4538 & 0.4647 \\
\hline \multirow{3}{*}{$J_{5}$} & MR & 0.8732 & 0.8320 & 0.7745 & 0.7887 & 0.8287 & 0.8481 & 0.8347 & 0.8252 & 0.8349 & 0.8266 \\
\hline & TMD & 0.7392 & 0.7462 & 0.7447 & 0.7745 & 0.7797 & 0.8761 & 0.8933 & 0.9012 & 0.9073 & 0.8935 \\
\hline & $\mathrm{MR}+\mathrm{TMD}$ & 0.6115 & 0.6103 & 0.5997 & 0.6294 & 0.6650 & 0.7164 & 0.7272 & 0.7319 & 0.7442 & 0.7424 \\
\hline \multirow{3}{*}{$J_{6}$} & MR & 1.0103 & 0.9840 & 0.9639 & 0.9694 & 0.9811 & 0.9863 & 0.9907 & 0.9939 & 0.9963 & 0.9977 \\
\hline & TMD & 1.0242 & 1.0281 & 1.0376 & 1.0582 & 0.9994 & 1.0887 & 1.0933 & 1.0965 & 1.0992 & 1.1022 \\
\hline & $\mathrm{MR}+\mathrm{TMD}$ & 0.9241 & 0.9170 & 0.9196 & 0.9369 & 0.9359 & 0.9730 & 0.9787 & 0.9832 & 0.9863 & 0.9888 \\
\hline \multirow{3}{*}{$J_{7}$} & MR & 0.1612 & 0.1773 & 0.1985 & 0.2254 & 0.2566 & 0.2817 & 0.2990 & 0.3100 & 0.3137 & 0.3170 \\
\hline & TMD & 0.7908 & 0.7995 & 0.8115 & 0.8461 & 0.8345 & 0.9250 & 0.9359 & 0.9450 & 0.9541 & 0.9628 \\
\hline & $\mathrm{MR}+\mathrm{TMD}$ & 0.1285 & 0.1434 & 0.1682 & 0.1957 & 0.2254 & 0.2580 & 0.2760 & 0.2878 & 0.2938 & 0.2983 \\
\hline \multirow{3}{*}{$J_{8}$} & MR & 0.2318 & 0.2467 & 0.2587 & 0.2862 & 0.3166 & 0.3401 & 0.3602 & 0.3768 & 0.3994 & 0.4291 \\
\hline & TMD & 0.7806 & 0.7889 & 0.7971 & 0.8314 & 0.8213 & 0.9110 & 0.9225 & 0.9299 & 0.9380 & 0.9446 \\
\hline & $\mathrm{MR}+\mathrm{TMD}$ & 0.1690 & 0.1839 & 0.2061 & 0.2359 & 0.2682 & 0.3022 & 0.3247 & 0.3442 & 0.3680 & 0.3931 \\
\hline
\end{tabular}


TABLe 10: Performance criteria for the proposed control systems under near-field earthquakes: regular structure.

\begin{tabular}{|c|c|c|c|c|c|c|c|c|c|c|c|}
\hline & \multicolumn{10}{|c|}{ PGA (g) } \\
\hline & & 0.1 & 0.2 & 0.3 & 0.4 & 0.5 & 0.6 & 0.7 & 0.8 & 0.9 & 1.0 \\
\hline \multirow{3}{*}{$J_{1}$} & MR & 0.8996 & 0.8835 & 0.8760 & 0.9045 & 0.9060 & 0.8786 & 0.8832 & 0.8919 & 0.8994 & 0.9042 \\
\hline & TMD & 0.9504 & 0.9424 & 0.9250 & 1.0004 & 1.0158 & 1.0053 & 0.9845 & 0.9765 & 0.9684 & 0.9650 \\
\hline & $\mathrm{MR}+\mathrm{TMD}$ & 0.8343 & 0.8294 & 0.8263 & 0.8801 & 0.8977 & 0.8809 & 0.8761 & 0.8778 & 0.8819 & 0.8802 \\
\hline \multirow{3}{*}{$J_{2}$} & MR & 0.9869 & 0.9924 & 1.0013 & 0.9835 & 0.9864 & 0.9944 & 0.9958 & 0.9961 & 0.9976 & 0.9989 \\
\hline & TMD & 0.9633 & 0.9825 & 0.9927 & 0.9940 & 0.9934 & 0.9944 & 0.9956 & 0.9963 & 0.9994 & 0.9985 \\
\hline & $\mathrm{MR}+\mathrm{TMD}$ & 0.9402 & 0.9657 & 0.9835 & 0.9708 & 0.9789 & 0.9888 & 0.9918 & 0.9930 & 0.9939 & 0.9984 \\
\hline \multirow{3}{*}{$J_{3}$} & MR & 0.2530 & 0.3781 & 0.4185 & 0.4299 & 0.4095 & 0.4023 & 0.3908 & 0.3940 & 0.4013 & 0.4162 \\
\hline & TMD & 0.9408 & 0.9537 & 0.9953 & 0.9882 & 0.9960 & 0.9962 & 0.9967 & 0.9978 & 1.0004 & 0.9991 \\
\hline & $\mathrm{MR}+\mathrm{TMD}$ & 0.2315 & 0.3525 & 0.4060 & 0.4171 & 0.3991 & 0.3926 & 0.3851 & 0.3880 & 0.3963 & 0.4093 \\
\hline \multirow{3}{*}{$J_{4}$} & MR & 0.3158 & 0.4041 & 0.4569 & 0.5487 & 0.6119 & 0.6426 & 0.6643 & 0.6845 & 0.6991 & 0.7098 \\
\hline & TMD & 0.9397 & 0.9430 & 0.9681 & 0.9825 & 0.9927 & 0.9889 & 0.9875 & 0.9892 & 0.9941 & 0.9929 \\
\hline & $\mathrm{MR}+\mathrm{TMD}$ & 0.2863 & 0.3851 & 0.4400 & 0.5464 & 0.6117 & 0.6397 & 0.6559 & 0.6744 & 0.6897 & 0.7043 \\
\hline \multirow{3}{*}{$J_{5}$} & MR & 0.8949 & 0.8584 & 0.9048 & 0.8791 & 0.8545 & 0.7862 & 0.7736 & 0.7832 & 0.7909 & 0.8108 \\
\hline & TMD & 0.8275 & 0.8521 & 0.8402 & 0.8780 & 0.9408 & 1.0532 & 1.0199 & 0.9791 & 0.9522 & 0.9387 \\
\hline & $\mathrm{MR}+\mathrm{TMD}$ & 0.6712 & 0.6967 & 0.7543 & 0.7549 & 0.7866 & 0.7738 & 0.7861 & 0.7854 & 0.7843 & 0.7817 \\
\hline \multirow{3}{*}{$J_{6}$} & MR & 0.9988 & 0.9873 & 0.9982 & 1.0052 & 1.0015 & 1.0019 & 1.0028 & 1.0034 & 1.0059 & 1.0099 \\
\hline & TMD & 0.8752 & 0.9194 & 0.9420 & 0.9657 & 0.9091 & 0.9811 & 0.9844 & 0.9867 & 0.9879 & 0.9888 \\
\hline & $\mathrm{MR}+\mathrm{TMD}$ & 0.8474 & 0.8889 & 0.9357 & 0.9637 & 0.9736 & 0.9807 & 0.9853 & 0.9882 & 0.9916 & 0.9993 \\
\hline \multirow{3}{*}{$J_{7}$} & MR & 0.1939 & 0.2660 & 0.3064 & 0.3343 & 0.3416 & 0.3425 & 0.3384 & 0.3370 & 0.3357 & 0.3355 \\
\hline & TMD & 0.8218 & 0.8699 & 0.8843 & 0.9294 & 0.8801 & 0.9538 & 0.9601 & 0.9632 & 0.9658 & 0.9666 \\
\hline & $\mathrm{MR}+\mathrm{TMD}$ & 0.1550 & 0.2354 & 0.2866 & 0.3179 & 0.3287 & 0.3266 & 0.3258 & 0.3255 & 0.3255 & 0.3267 \\
\hline \multirow{3}{*}{$J_{8}$} & MR & 0.2531 & 0.3364 & 0.4139 & 0.4776 & 0.4944 & 0.5149 & 0.5502 & 0.6047 & 0.6489 & 0.6837 \\
\hline & TMD & 0.8208 & 0.8679 & 0.8876 & 0.9285 & 0.8806 & 0.9609 & 0.9691 & 0.9662 & 0.9576 & 0.9558 \\
\hline & $\mathrm{MR}+\mathrm{TMD}$ & 0.1988 & 0.2947 & 0.3825 & 0.4400 & 0.4831 & 0.5163 & 0.5563 & 0.6038 & 0.6458 & 0.6703 \\
\hline
\end{tabular}

TABLE 11: Performance criteria for the proposed control systems under near-field earthquakes: reduced stiffness in the 1st-5th stories.

\begin{tabular}{|c|c|c|c|c|c|c|c|c|c|c|c|}
\hline & \multicolumn{10}{|c|}{ PGA (g) } \\
\hline & & 0.1 & 0.2 & 0.3 & 0.4 & 0.5 & 0.6 & 0.7 & 0.8 & 0.9 & 1.0 \\
\hline \multirow{3}{*}{$J_{1}$} & MR & 0.9001 & 0.8625 & 0.8512 & 0.8845 & 0.9096 & 0.8719 & 0.8794 & 0.8837 & 0.8925 & 0.9063 \\
\hline & TMD & 0.9618 & 0.9464 & 0.9416 & 0.9779 & 1.0128 & 1.0015 & 0.9862 & 0.9733 & 0.9660 & 0.9712 \\
\hline & MR + TMD & 0.8258 & 0.8135 & 0.8044 & 0.8588 & 0.8980 & 0.8714 & 0.8724 & 0.8697 & 0.8719 & 0.8805 \\
\hline \multirow{3}{*}{$J_{2}$} & MR & 0.9966 & 0.9814 & 1.0137 & 0.9947 & 0.9859 & 0.9844 & 0.9846 & 0.9890 & 0.9987 & 1.0112 \\
\hline & TMD & 0.9785 & 0.9751 & 0.9943 & 0.9921 & 0.9985 & 0.9959 & 0.9967 & 0.9959 & 0.9977 & 0.9979 \\
\hline & MR + TMD & 0.9683 & 0.9620 & 1.0053 & 0.9931 & 0.9814 & 0.9782 & 0.9765 & 0.9842 & 0.9939 & 1.0080 \\
\hline \multirow{3}{*}{$J_{3}$} & MR & 0.2736 & 0.3949 & 0.4632 & 0.4864 & 0.4530 & 0.4154 & 0.4100 & 0.4101 & 0.4117 & 0.4117 \\
\hline & TMD & 0.9375 & 0.9445 & 0.9826 & 0.9976 & 0.9914 & 0.9945 & 0.9946 & 0.9966 & 0.9980 & 0.9992 \\
\hline & $\mathrm{MR}+\mathrm{TMD}$ & 0.2523 & 0.3776 & 0.4495 & 0.4759 & 0.4377 & 0.4097 & 0.4041 & 0.4091 & 0.4086 & 0.4079 \\
\hline \multirow{3}{*}{$J_{4}$} & MR & 0.2968 & 0.3977 & 0.4682 & 0.5722 & 0.6171 & 0.6350 & 0.6498 & 0.6709 & 0.6882 & 0.7012 \\
\hline & TMD & 0.9438 & 0.9456 & 0.9684 & 0.9832 & 0.9925 & 0.9913 & 0.9879 & 0.9875 & 0.9866 & 0.9900 \\
\hline & MR + TMD & 0.2642 & 0.3756 & 0.4538 & 0.5659 & 0.6133 & 0.6310 & 0.6431 & 0.6610 & 0.6767 & 0.6918 \\
\hline \multirow{3}{*}{$J_{5}$} & MR & 0.8887 & 0.8296 & 0.8577 & 0.8245 & 0.8271 & 0.7987 & 0.7681 & 0.7533 & 0.7775 & 0.8102 \\
\hline & TMD & 0.8350 & 0.8527 & 0.8724 & 0.8834 & 0.9554 & 1.0363 & 1.0037 & 0.9691 & 0.9498 & 0.9541 \\
\hline & $\mathrm{MR}+\mathrm{TMD}$ & 0.6614 & 0.6747 & 0.7284 & 0.7217 & 0.7225 & 0.7706 & 0.7447 & 0.7472 & 0.7580 & 0.7902 \\
\hline \multirow{3}{*}{$J_{6}$} & MR & 0.9816 & 0.9511 & 0.9750 & 0.9976 & 1.0036 & 1.0031 & 1.0012 & 1.0039 & 1.0076 & 1.0115 \\
\hline & TMD & 0.8801 & 0.9181 & 0.9424 & 0.9692 & 0.9397 & 0.9837 & 0.9866 & 0.9885 & 0.9896 & 0.9905 \\
\hline & $\mathrm{MR}+\mathrm{TMD}$ & 0.8225 & 0.8499 & 0.9120 & 0.9547 & 0.9338 & 0.9793 & 0.9829 & 0.9893 & 0.9957 & 1.0015 \\
\hline \multirow{3}{*}{$J_{7}$} & MR & 0.2374 & 0.2950 & 0.3304 & 0.3552 & 0.3585 & 0.3506 & 0.3500 & 0.3504 & 0.3538 & 0.3541 \\
\hline & TMD & 0.8322 & 0.8687 & 0.8913 & 0.9319 & 0.9084 & 0.9539 & 0.9597 & 0.9643 & 0.9676 & 0.9710 \\
\hline & $\mathrm{MR}+\mathrm{TMD}$ & 0.1957 & 0.2549 & 0.3027 & 0.3343 & 0.3256 & 0.3335 & 0.3352 & 0.3385 & 0.3433 & 0.3451 \\
\hline \multirow{3}{*}{$J_{8}$} & MR & 0.2390 & 0.3246 & 0.4001 & 0.4620 & 0.4935 & 0.5152 & 0.5519 & 0.5917 & 0.6423 & 0.6833 \\
\hline & TMD & 0.8307 & 0.8648 & 0.8975 & 0.9260 & 0.9033 & 0.9622 & 0.9707 & 0.9666 & 0.9609 & 0.9644 \\
\hline & $\mathrm{MR}+\mathrm{TMD}$ & 0.1912 & 0.2790 & 0.3728 & 0.4352 & 0.4550 & 0.4978 & 0.5371 & 0.5885 & 0.6388 & 0.6765 \\
\hline
\end{tabular}


TABLE 12: Performance criteria for the proposed control systems under near-field earthquakes: reduced stiffness in the 1st story.

\begin{tabular}{|c|c|c|c|c|c|c|c|c|c|c|c|}
\hline & \multicolumn{10}{|c|}{ PGA (g) } \\
\hline & & 0.1 & 0.2 & 0.3 & 0.4 & 0.5 & 0.6 & 0.7 & 0.8 & 0.9 & 1.0 \\
\hline \multirow{3}{*}{$J_{1}$} & MR & 0.8681 & 0.8236 & 0.8237 & 0.8786 & 0.8785 & 0.8497 & 0.8549 & 0.8645 & 0.8731 & 0.8830 \\
\hline & TMD & 0.9559 & 0.9458 & 0.9320 & 1.0034 & 1.0156 & 1.0035 & 0.9861 & 0.9775 & 0.9681 & 0.9640 \\
\hline & $\mathrm{MR}+\mathrm{TMD}$ & 0.7869 & 0.7758 & 0.7832 & 0.8458 & 0.8623 & 0.8469 & 0.8466 & 0.8498 & 0.8583 & 0.8639 \\
\hline \multirow{3}{*}{$J_{2}$} & MR & 0.9984 & 1.0051 & 1.0128 & 0.9941 & 0.9938 & 0.9985 & 0.9986 & 0.9975 & 1.0058 & 1.0206 \\
\hline & TMD & 0.9630 & 0.9834 & 0.9891 & 0.9925 & 0.9917 & 0.9956 & 0.9958 & 0.9956 & 0.9985 & 0.9996 \\
\hline & $\mathrm{MR}+\mathrm{TMD}$ & 0.9549 & 0.9707 & 0.9932 & 0.9784 & 0.9838 & 0.9962 & 0.9907 & 0.9925 & 1.0012 & 1.0167 \\
\hline \multirow{3}{*}{$J_{3}$} & MR & 0.3087 & 0.4276 & 0.4745 & 0.4932 & 0.4584 & 0.4369 & 0.4156 & 0.4033 & 0.4065 & 0.4150 \\
\hline & TMD & 0.9417 & 0.9531 & 0.9970 & 0.9940 & 0.9944 & 0.9964 & 0.9972 & 1.0007 & 1.0001 & 0.9992 \\
\hline & $\mathrm{MR}+\mathrm{TMD}$ & 0.2772 & 0.3995 & 0.4614 & 0.4751 & 0.4408 & 0.4259 & 0.4097 & 0.3960 & 0.4025 & 0.4066 \\
\hline \multirow{3}{*}{$J_{4}$} & MR & 0.2444 & 0.3564 & 0.4233 & 0.5175 & 0.5732 & 0.6116 & 0.6363 & 0.6556 & 0.6725 & 0.6858 \\
\hline & TMD & 0.9424 & 0.9458 & 0.9683 & 0.9920 & 0.9914 & 0.9894 & 0.9870 & 0.9868 & 0.9896 & 0.9903 \\
\hline & $\mathrm{MR}+\mathrm{TMD}$ & 0.2172 & 0.3372 & 0.4098 & 0.5093 & 0.5694 & 0.6093 & 0.6292 & 0.6474 & 0.6626 & 0.6800 \\
\hline \multirow{3}{*}{$J_{5}$} & MR & 0.8400 & 0.7919 & 0.8636 & 0.8401 & 0.8198 & 0.7497 & 0.7072 & 0.7120 & 0.7316 & 0.7671 \\
\hline & TMD & 0.8295 & 0.8565 & 0.8592 & 0.8918 & 0.9525 & 1.0556 & 1.0175 & 0.9827 & 0.9563 & 0.9472 \\
\hline & $\mathrm{MR}+\mathrm{TMD}$ & 0.6154 & 0.6364 & 0.7172 & 0.7397 & 0.7504 & 0.7172 & 0.6987 & 0.7112 & 0.7270 & 0.7521 \\
\hline \multirow{3}{*}{$J_{6}$} & MR & 1.0084 & 0.9903 & 0.9966 & 1.0077 & 1.0037 & 1.0048 & 1.0052 & 1.0058 & 1.0093 & 1.0161 \\
\hline & TMD & 0.8737 & 0.9196 & 0.9443 & 0.9669 & 0.9371 & 0.9816 & 0.9851 & 0.9869 & 0.9882 & 0.9892 \\
\hline & $\mathrm{MR}+\mathrm{TMD}$ & 0.8523 & 0.8918 & 0.9425 & 0.9704 & 0.9780 & 0.9844 & 0.9888 & 0.9924 & 0.9972 & 1.0043 \\
\hline \multirow{3}{*}{$J_{7}$} & MR & 0.2804 & 0.3288 & 0.3647 & 0.3895 & 0.3869 & 0.3808 & 0.3748 & 0.3739 & 0.3723 & 0.3712 \\
\hline & TMD & 0.8236 & 0.8687 & 0.8934 & 0.9336 & 0.9038 & 0.9565 & 0.9603 & 0.9633 & 0.9657 & 0.9677 \\
\hline & $\mathrm{MR}+\mathrm{TMD}$ & 0.2183 & 0.2788 & 0.3309 & 0.3594 & 0.3638 & 0.3572 & 0.3562 & 0.3571 & 0.3568 & 0.3558 \\
\hline \multirow{3}{*}{$J_{8}$} & MR & 0.1808 & 0.2935 & 0.3720 & 0.4405 & 0.4669 & 0.4860 & 0.5142 & 0.5487 & 0.5966 & 0.6395 \\
\hline & TMD & 0.8226 & 0.8665 & 0.8964 & 0.9313 & 0.9082 & 0.9660 & 0.9740 & 0.9746 & 0.9689 & 0.9591 \\
\hline & $\mathrm{MR}+\mathrm{TMD}$ & 0.1481 & 0.2558 & 0.3479 & 0.4176 & 0.4542 & 0.4846 & 0.5124 & 0.5530 & 0.5958 & 0.6376 \\
\hline
\end{tabular}

TABLE 13: Performance criteria for the proposed control systems under near-field earthquakes: reduced stiffness in the 5th story.

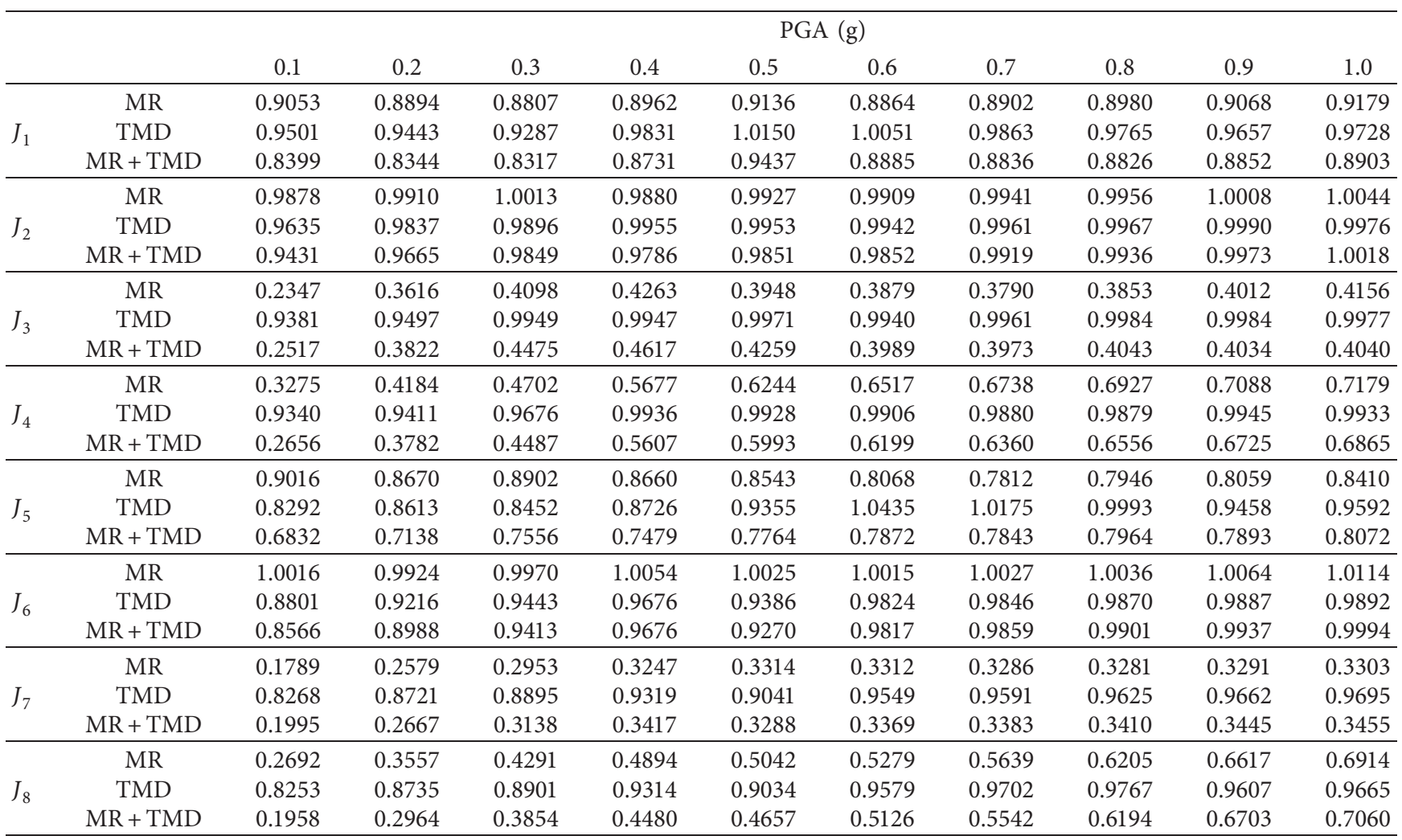




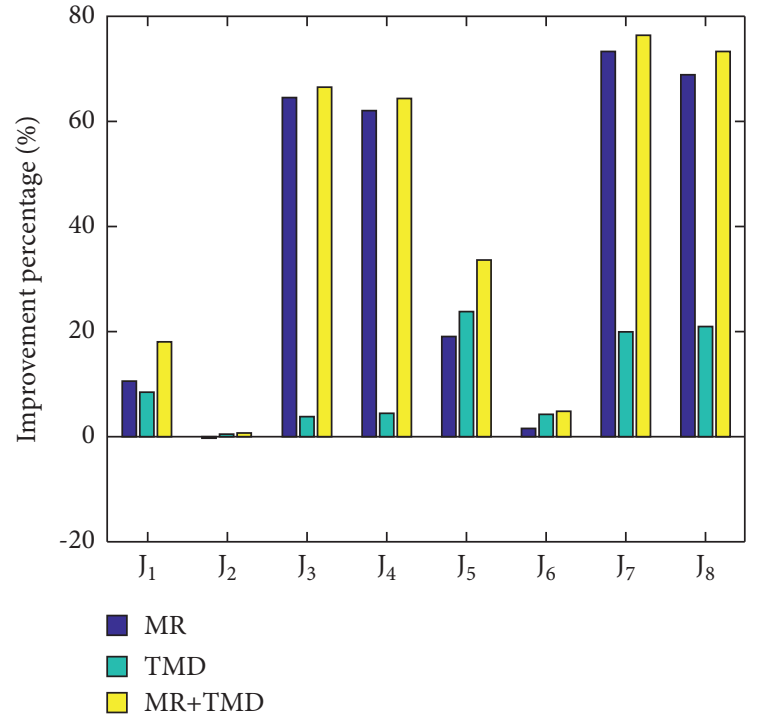

(a)

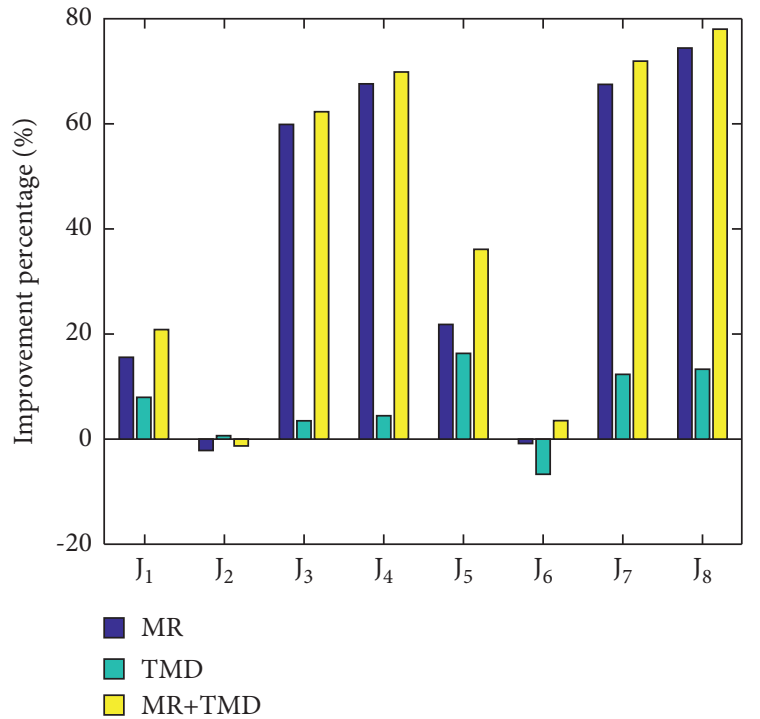

(c)

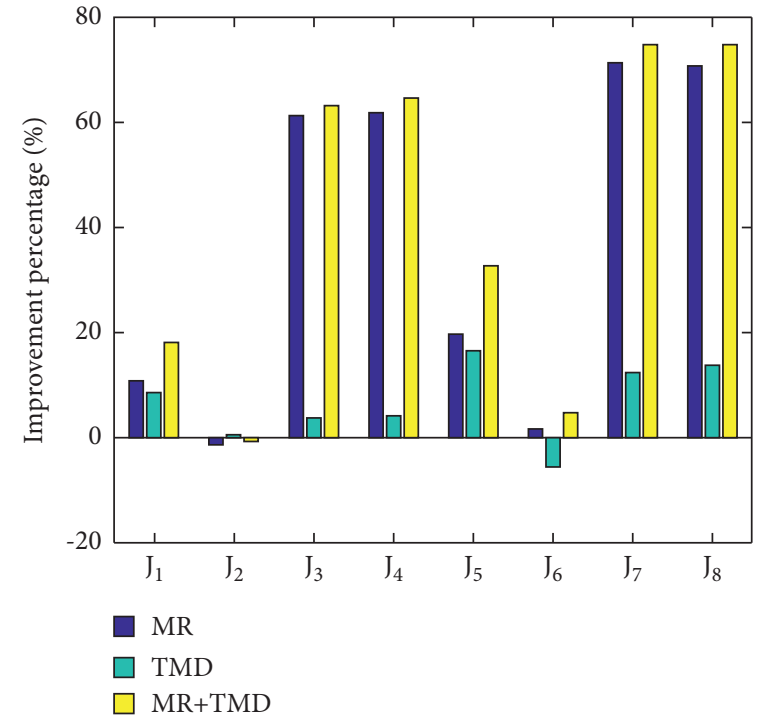

(b)

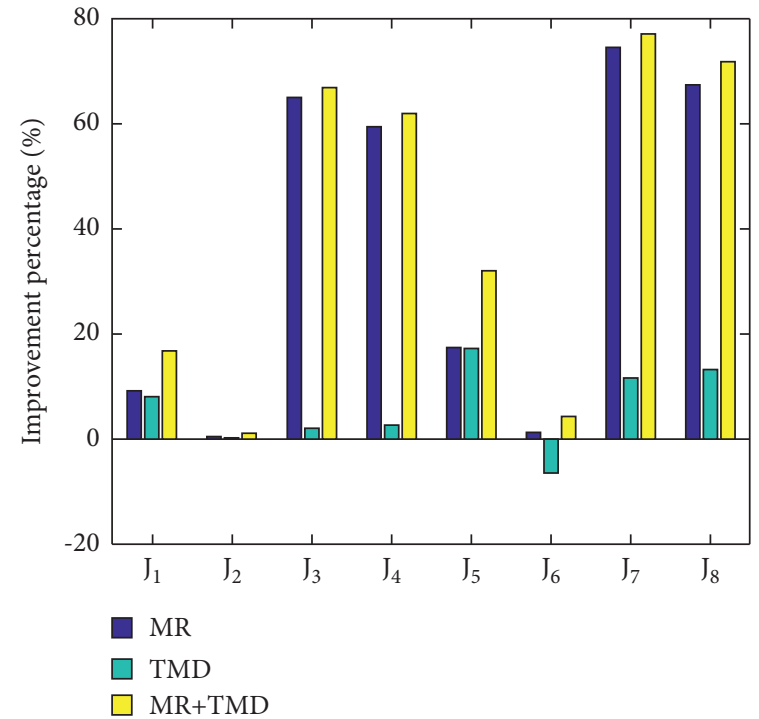

(d)

Figure 5: Average percentage of improvement in performance criteria: (a) the regular structure subjected to far-field earthquakes, (b) stiffness irregularity in the 1st-5th stories of structure subjected to far-field earthquakes, (c) stiffness irregularity in the 1st story of structure subjected to far-field earthquakes, (d) stiffness irregularity in the 5th story of structure subjected to far-field earthquakes.

is a noticeable drop in efficiency in large PGAs. Accordingly, there is no significant difference between the combined MRTMD system and the MR damper alone, for large PGA values. Comparing the results of near-field and far-field earthquakes, it is observed that the performance of TMD dampers in the far-field earthquakes is much higher than the near-field earthquakes, so that, in far-field earthquakes with PGA values less than $0.3 \mathrm{~g}$, it shows better performance than MR dampers. However, for near-field earthquakes, the MR control system always shows better performance. $J_{2}$ indicates the ability of the control system to reduce the acceleration response. The results obtained for this criterion considering different structures and excitation records show no significant improvement in acceleration response. $J_{3}$ and
$J_{4}$ measure the efficiency of the control system to reduce the base shear and base moment. Effective reduction of these criteria leads to reduced base shear and base moment as well as the earthquake-induced forces in structural elements. Comparing the results presented for these criteria shows that the control strategies of including the MR damper lead to smaller base shear and base moments compared with TMD due to having a damping mechanism that directly transmits the shear force of the lowest story to the ground.

With increase in PGA, the efficiency of all control systems, both passive and semiactive, is decreased. Like $J_{1}, J_{5}$ also expresses the efficiency of control systems to reduce the displacement of the structure except that it considered the normed response to evaluate the performance. A reduction 


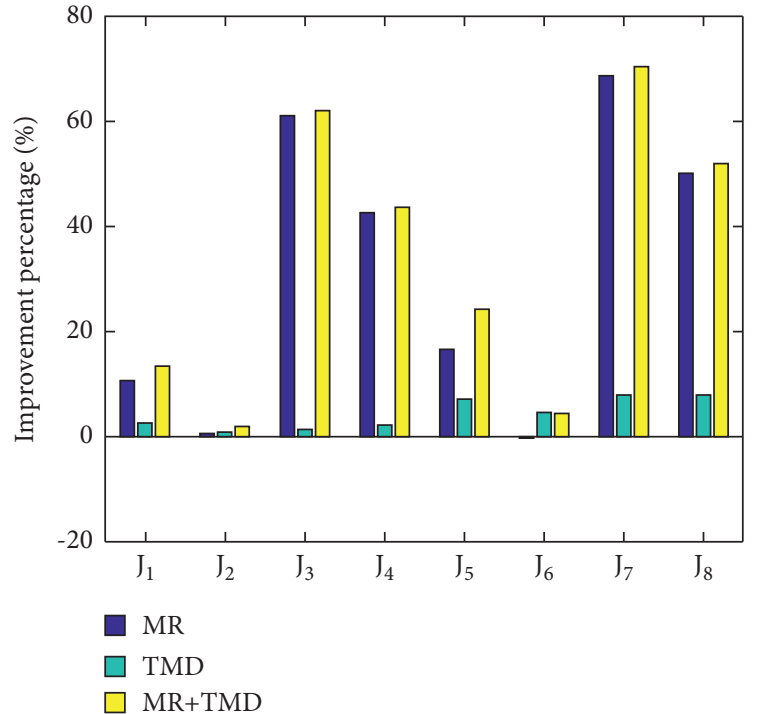

(a)

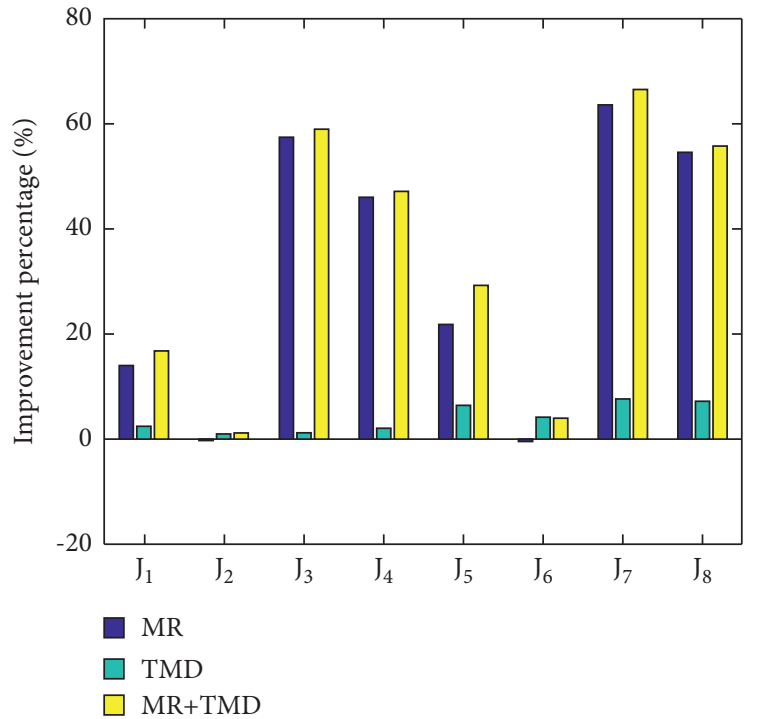

(c)

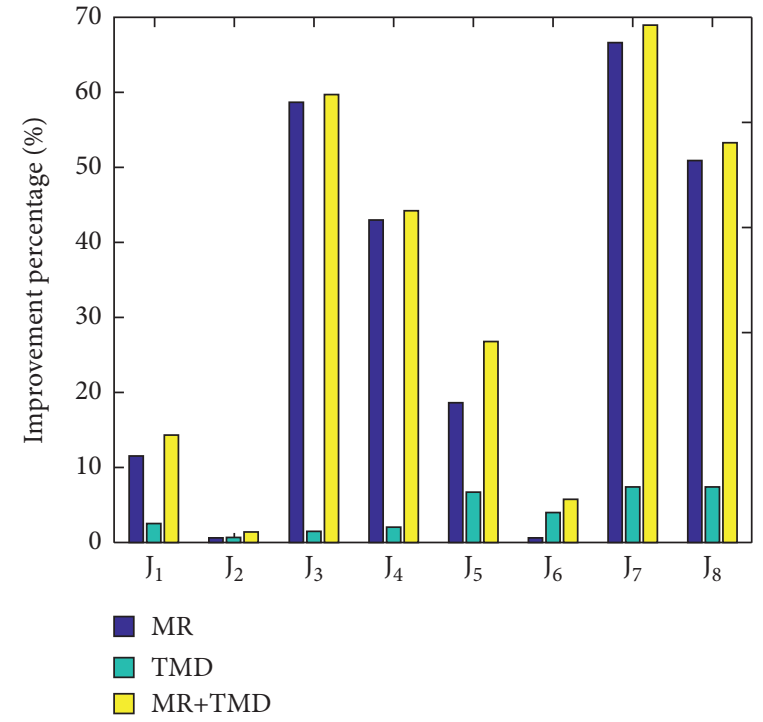

(b)

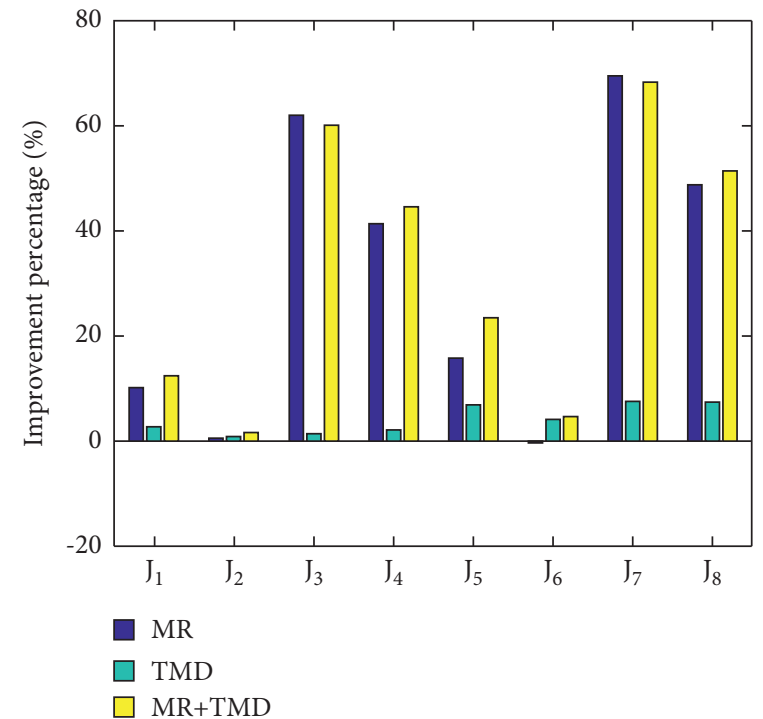

(d)

FiguRE 6: Average percentage of improvement in performance criteria: (a) regular structure subjected to near-field earthquakes, (b) stiffness irregularity in the 1st-5th stories of structure subjected to near-field earthquakes, (c) stiffness irregularity in the 1st story of structure subjected to near-field earthquakes, (d) stiffness irregularity in the 5th story of structure subjected to near-field earthquakes.

in this criterion indicates the improved performance of the control system in protecting the stability of the structure. Improving this criterion means faster damping of the structural vibrations. The control system consisting of MR damper is stable against variation of PGA value and shows no significant sensitivity to the PGA. Even with increasing the PGA, its performance increases to some extent. The TMD, on the other hand, clearly loses performance as the PGA increases. The combined MR-TMD system performs better than the other two systems. But, due to the sensitivity of TMD to the PGA, this strategy also loses performance with the increase in PGA. The combined MR-TMD system shows the best performance while being subjected to farfield earthquakes with any PGA value, while, in near-field earthquakes with increasing the PGA, there is no significant difference between this system and the system with MR damper alone. Like $J_{2}, J_{6}$ describes the ability of the control system to reduce the acceleration of the structure except that it uses the normed values of acceleration response. The system with MR damper shows no significant sensitivity to the PGA when subjected to far- and near-field earthquakes, while increased PGA leads to reduced performance in the TMD damper as well as the combined MR-TMD system. In far-field earthquakes, the system with both MR damper and TMD shows the best performance in reducing $J_{6}$, while, in near-field earthquakes, there is no significant difference between this control system and the TMD system. Like $J_{3}$ and $J_{4}, J_{7}$ and $J_{8}$ describe the efficiency of the control system 
to reduce the base shear and base moment except that the normed response values are considered. Considering these criteria, there is no significant difference in performance between semiactive strategies. In fact, with the addition of the TMD, the performance of the MR damper is not significantly improved.

Figures 5(a)-5(d) show the average percentage of improvement in the performance criteria obtained for far-field earthquakes. According to these figures, the combined MRTMD system shows the best performance for all criteria. It should be also mentioned that there is no significant difference between the performance of this system and the system with MR damper alone in terms of $J_{2}, J_{3}, J_{4}, J_{7}$, and $J_{8}$. Therefore, if the main objective is to reduce the maximum and normed displacement response, it is recommended to use TMD damper along with MR damper. Otherwise, using TMD will only incur additional costs. This conclusion is also true for irregular structures, as the use of TMD only worsens the normed acceleration of the structure. However, the proposed strategies are not designed to reduce acceleration and therefore should not be expected to do so.

Figures 6(a)-6(d) show the average percentage of improvement in the performance criteria obtained for near-field earthquakes. It is observed from the figures that the combined MR-TMD control system has the best performance in terms of all performance criteria. However, since the TMD alone is not effective in near-field earthquakes, there is no significant difference between using MR damper alone and MR damper together with TMD, except for $J_{5}$ which indicates further reduction in normed displacement due to the use of TMD. Therefore, the use of TMD dampers, either alone or together with MR dampers, will not significantly increase the responses in near-field earthquakes.

\section{Conclusion}

In the present study, in order to control the vibrations of structures with stiffness irregularity, three different control systems incorporating MR damper, TMD, and combined MR-TMD devices were proposed. To investigate the performance of the control systems in the stiffness irregular structures, a regular structure as well as three irregular structures, with the same first mode period, stiffness, and yielding base shear, was used as reference structures. Irregular structures were simulated by reducing the stiffness of different stories in the regular structure. The irregularities were applied to the $1^{\text {st }}-5^{\text {th }}$ story, the $1^{\text {st }}$ story, and the $5^{\text {th }}$ story to simulate three different irregular structures. These structures were subjected to 7 far-field and 7 near-field earthquakes to separately examine the performance of the control systems. The MR damper installed at the first story together with a fuzzy controller, which determines the required voltage based on the relative velocity as the input from the sensors, was used as one of the control strategies. The TMD with a mass of 2 percent of the total mass of the structure was assumed to be installed at the highest level of the structure, and the stiffness and damping parameters were determined through conventional relations.
The residual displacement results showed that, for farfield earthquakes, the TMD shows a higher performance than the MR damper, and the structures controlled by the TMD damper have less residual displacement. In these earthquakes, by simultaneous use of these two dampers, the performance was successfully enhanced in all structures, and the least residual displacement was recorded. In near-field earthquakes, the TMD showed very poor performance in reducing residual displacement, compared with the MR damper. However, with the simultaneous use of these two dampers, the performance was significantly improved, so that the least residual displacements due to near-field earthquakes were observed. According to the results presented for IDA analyses, the sensitivity of different performance criteria to the PGA of earthquake records was also examined. Accordingly, the MR damper showed the least sensitivity to $J_{1}, J_{2}, J_{5}, J_{6}$, and $J_{7}$, and the TMD showed the least sensitivity to $J_{3}, J_{4}$, and $J_{8}$. The obtained performance criteria also showed that the simultaneous use of MR damper and TMD has the best performance, followed by the MR damper with a slight difference in second place and TMD in third place [27].

\section{Data Availability}

The data used to support the findings of this study are available from the corresponding author upon request.

\section{Conflicts of Interest}

The authors declare that they have no conflicts of interest.

\section{References}

[1] A. Loghmani, A. Mortezaei, and A. Hemmati, "A new equation based on PGA to provide sufficient separation distance between two irregular buildings in plan," Earthquake and Structures, vol. 18, no. 5, pp. 543-553, 2020.

[2] S. Gunay, K. Mosalam, J. Archbold et al., "Preliminary virtual reconnaissance report (PVRR)," 2020. PRJ-2953.

[3] F. Michalis, V. Dimitrios, and P. Manolis, "Evaluation of the influence of vertical irregularities on the seismic performance of a nine-storey steel frame," Earthquake Engineering \& Structural Dynamics, vol. 35, no. 12, pp. 1489-1509, 2006.

[4] K. Le-Trung, K. Lee, J. Lee, and D. H. Lee, "Evaluation of seismic behaviour of steel special moment frame buildings with vertical irregularities," The Structural Design of Tall and Special Buildings, vol. 21, no. 3, pp. 215-232, 2012.

[5] R. Oyguc, C. Toros, and A. E. Abdelnaby, "Seismic behavior of irregular reinforced-concrete structures under multiple earthquake excitations," Soil Dynamics and Earthquake Engineering, vol. 104, pp. 15-32, 2018.

[6] S. Naveen E, N. M. Abraham, and A. K. S D, "Analysis of irregular structures under earthquake loads," Procedia Structural Integrity, vol. 14, pp. 806-819, 2019.

[7] M. Khatami, M. Gerami, A. Kheyroddin, and N. Siahpolo, "The effect of irregularity of lateral stiffness in estimating the separation gap of adjacent frames," KSCE Journal of Civil Engineering, vol. 24, no. 1, pp. 166-177, 2020.

[8] O. Sonawane and S. B. Walzade, "Effect of base isolation in multistoried RC regular and irregular building using time 
history analysis," International Journal of Engineering Research and Science, vol. 4, no. 5, pp. 30-37, 2018.

[9] Z. Alam, C. Zhang, and B. Samali, "The role of viscoelastic damping on retrofitting seismic performance of asymmetric reinforced concrete structures," Earthquake Engineering and Engineering Vibration, vol. 19, no. 1, pp. 223-237, 2020.

[10] O. Lavan, "Optimal design of viscous dampers and their supporting members for the seismic retrofitting of 3D irregular frame structures," Journal of Structural Engineering, vol. 141, no. 11, 2015.

[11] S. Pathan, D. Kakade, and A. Wadekar, "Seismic response control of asymmetric building using friction damper and shear wall," Journal of Structural Technology, vol. 2, no. 2, pp. 1-5, 2017.

[12] S. Javadinasab Hormozabad and S. Zahrai, "Innovative adaptive viscous damper to improve seismic control of structures," Journal of Vibration and Control, vol. 25, no. 12, pp. 1833-1851, 2019.

[13] V. Mohsenian and A. Mortezaei, "A new energy-absorbing system for seismic retrofitting of frame structures with slender braces," Bulletin of Earthquake Engineering, vol. 17, no. 5, pp. 2715-2739, 2019.

[14] S. M. Nigdeli and M. H. Boduroğlu, "Active tendon control of torsionally irregular structures under near-fault ground motion excitation," Computer-Aided Civil and Infrastructure Engineering, vol. 28, no. 9, pp. 718-736, 2013.

[15] F. Mazza, "Seismic demand of base-isolated irregular structures subjected to pulse-type earthquakes," Soil Dynamics and Earthquake Engineering, vol. 108, pp. 111-129, 2018.

[16] H. Naderpour, A. Kiani, and A. Kheyroddin, "Structural control of RC buildings subjected to near-fault ground motions in terms of tuned mass dampers," Scientia Iranica, vol. 27, no. 1, pp. 122-133, 2020.

[17] M. G. Soto and H. Adeli, "Optimum tuning parameters of tuned mass dampers for vibration control of irregular highrise building structures," Journal of Civil Engineering and Management, vol. 20, no. 5, pp. 609-620, 2014.

[18] M. Babaei and A. Moniri, "Use of tuned mass dampers in controlling the vibrations of steel structures with vertical irregularity of mass," Journal of computational engineering, vol. 1, no. 2, pp. 83-94, 2018.

[19] A. Bathaei, S. M. Zahrai, and M. Ramezani, "Semi-active seismic control of an 11-DOF building model with TMD+MR damper using type-1 and -2 fuzzy algorithms," Journal of Vibration and Control, vol. 24, no. 13, pp. 2938-2953, 2018.

[20] S. Javadinasab Hormozabad and A. K. Ghorbani-Tanha, "Semi-active fuzzy control of Lali Cable-Stayed Bridge using MR dampers under seismic excitation," Frontiers of Structural and Civil Engineering, vol. 14, no. 3, pp. 706-721, 2020.

[21] S. Salari, S. Javadinasab Hormozabad, A. K. Ghorbani-Tanha, and M. Rahimian, "Innovative mobile TMD system for semiactive vibration control of inclined sagged cables," KSCE Journal of Civil Engineering, vol. 23, no. 2, pp. 641-653, 2019.

[22] M. Khazaei, R. Vahdani, and A. Kheyroddin, "Optimal location of multiple tuned mass dampers in irregular tall steel buildings plan," Shock and Viberation, vol. 2020, Article ID 9072637, 20 pages, 2020.

[23] M. Pirizadeh and H. Shakib, "Probabilistic seismic performance evaluation of non-geometric vertically irregular steel buildings," Journal of Constructional Steel Research, vol. 82, pp. 88-98, 2013.

[24] J. E. Brock, "A note on the damped vibration absorber," Journal of Applied Mechanics, vol. 13, no. 4, p. 284, 1946.
[25] T. Ioi and K. Ikeda, "On the dynamic vibration damped absorber of the vibration system," Bulletin of JSME, vol. 21, no. 151, pp. 64-71, 1978.

[26] S.-Y. Ok, D.-S. Kim, K.-S. Park, and H.-M. Koh, "Semi-active fuzzy control of cable-stayed bridges using magneto-rheological dampers," Engineering Structures, vol. 29, no. 5, pp. 776-788, 2007.

[27] M. Ramezani, A. Bathaei, and S. M. Zahrai, "Designing fuzzy systems for optimal parameters of TMDs to reduce seismic response of tall buildings," Smart Structures and Systems, vol. 20, no. 1, pp. 61-74, 2017.

[28] H. S. Kim and J. W. Kang, "Semi-active fuzzy control of a wind-excited tall building using multi-objective genetic algorithm," Engineering Structures, vol. 41, pp. 242-257, 2012. 